IUCrJ

ISSN 2052-2525

BIOLOGY|MEDICINE

Received 13 August 2020

Accepted 12 October 2020

Edited by J. L. Smith, University of Michigan, USA

₹ These authors contributed equally to this work.

Keywords: neutron/X-ray diffraction; urate oxidase; protein perdeuteration; cofactorindependent oxidase; biomolecular simulations.

PDB reference: perdeuterated urate oxidase from Aspergillus flavus in complex with 8-azaxanthine, $7 \mathrm{aOO}$

Supporting information: this article has supporting information at www.iucrj.org

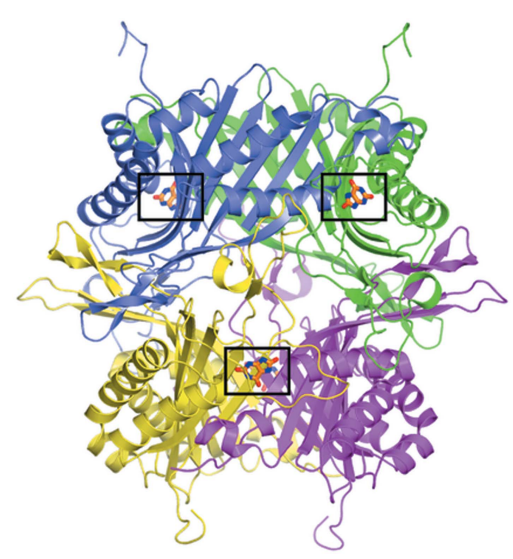

\section{Joint neutron/X-ray crystal structure of a mechan- istically relevant complex of perdeuterated urate oxidase and simulations provide insight into the hydration step of catalysis}

\author{
Lindsay McGregor, ${ }^{\mathrm{a}, \mathrm{b}} \neq$ Tamás Földes, ${ }^{\mathrm{c}, \mathrm{d}} \neq$ Soi Bui, ${ }^{\mathrm{a}}$ Martine Moulin, ${ }^{\mathrm{e}}$ Nicolas \\ Coquelle, ${ }^{\mathrm{b}}$ Matthew P. Blakeley, ${ }^{\mathrm{b}}$ Edina Rosta ${ }^{\mathrm{c}, \mathrm{d}}$ and Roberto A. Steiner ${ }^{\mathrm{a} *}$
}

${ }^{\mathbf{a}}$ Randall Centre for Cell and Molecular Biophysics, King's College London, London SE1 1UL, United Kingdom, 'barge Scale Structures Group, Institut Laue-Langevin, 71 avenue des Martyrs, 38042 Cedex 9, Grenoble, France, ${ }^{\mathbf{c} D e p a r t m e n t}$ of Chemistry, King's College London, London SE1 1DB, United Kingdom, 'Department of Physics and Astronomy, University College, London WC1E 6BT, United Kingdom, and ' ${ }^{\mathbf{e}}$ ife Sciences Group, Institut Laue-Langevin, 71 avenue des Martyrs, 38042 Cedex 9, Grenoble, France. *Correspondence e-mail: roberto.steiner@kcl.ac.uk

Cofactor-independent urate oxidase (UOX) is an $\sim 137 \mathrm{kDa}$ tetrameric enzyme essential for uric acid (UA) catabolism in many organisms. UA is first oxidized by $\mathrm{O}_{2}$ to dehydroisourate (DHU) via a peroxo intermediate. DHU then undergoes hydration to 5-hydroxyisourate (5HIU). At different stages of the reaction both catalytic $\mathrm{O}_{2}$ and water occupy the 'peroxo hole' above the organic substrate. Here, high-resolution neutron/X-ray crystallographic analysis at room temperature has been integrated with molecular dynamics simulations to investigate the hydration step of the reaction. The joint neutron/X-ray structure of perdeuterated Aspergillus flavus UOX in complex with its 8-azaxanthine (8AZA) inhibitor shows that the catalytic water molecule (W1) is present in the peroxo hole as neutral $\mathrm{H}_{2} \mathrm{O}$, oriented at $45^{\circ}$ with respect to the ligand. It is stabilized by Thr57 and Asn254 on different UOX protomers as well as by an $\mathrm{O}-\mathrm{H} \cdots \pi$ interaction with 8AZA. The active site Lys10-Thr57 dyad features a charged Lys10- $\mathrm{NH}_{3}^{+}$side chain engaged in a strong hydrogen bond with Thr $57^{\mathrm{OG} 1}$, while the Thr57 $7^{\mathrm{OG} 1-\mathrm{HG} 1}$ bond is rotationally dynamic and oriented toward the $\pi$ system of the ligand, on average. Our analysis offers support for a mechanism in which W1 performs a nucleophilic attack on DHU ${ }^{\mathrm{C5}}$ with Thr $57^{\mathrm{HG} 1}$ central to a Lys10-assisted proton-relay system. Room-temperature crystallography and simulations also reveal conformational heterogeneity for Asn254 that modulates W1 stability in the peroxo hole. This is proposed to be an active mechanism to facilitate $\mathrm{W} 1 / \mathrm{O}_{2}$ exchange during catalysis.

\section{Introduction}

In many organisms, urate oxidase (UOX) is an essential enzyme that catalyses the $\mathrm{O}_{2}$-dependent degradation of uric acid (UA) to 5-hydroxyisourate (5HIU) (Kahn et al., 1997). Humans, however, lack UOX, as it was lost by pseudogenization during primate evolution resulting in inactivation of the uricolytic pathway (Oda et al., 2002). Therefore, recombinant UOX finds a therapeutic application for the enzymatic treatment of severe hyperuricemia and prevents the UA burst accompanying tumour lysis after certain chemotherapy treatments (Terkeltaub, 2010).

Mechanistically, UOX-mediated degradation of UA follows two sequential steps: (1) an initial oxidation step whereby UA reacts with $\mathrm{O}_{2}$ to yield dehydroisourate (DHU) via a 5peroxoisourate (5PIU) intermediate and (2) a hydration step in which DHU is hydroxylated to 5HIU [Fig. 1(a)] (Kahn, 1999; Wei et al., 2017). The latter is ultimately transformed to 
(a)

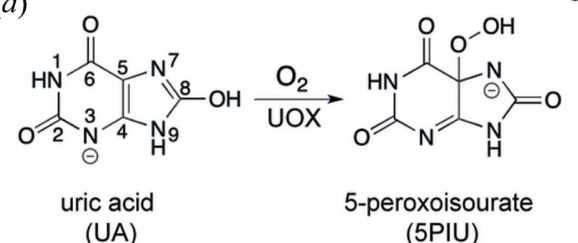

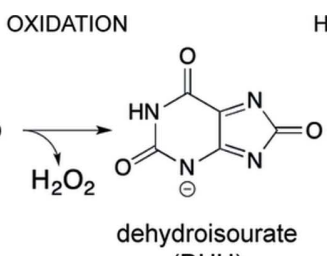
(DHU)
HYDRATION

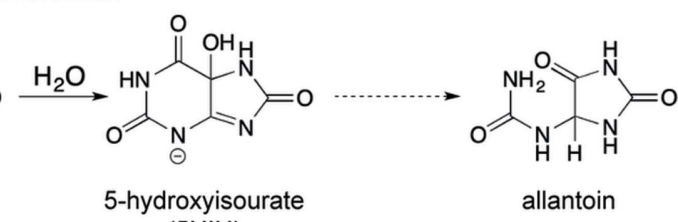
(5HIU) (b)

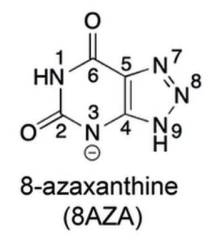

(c)

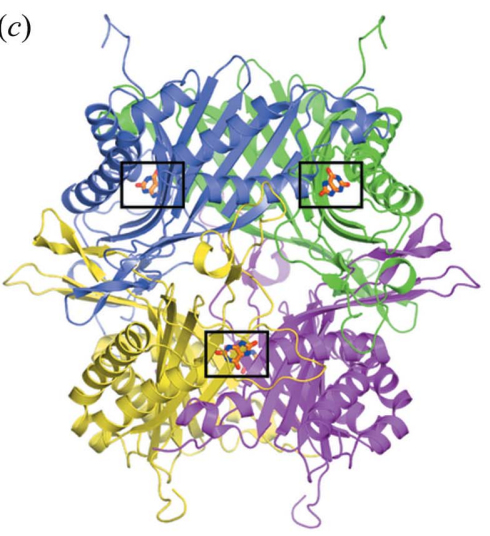

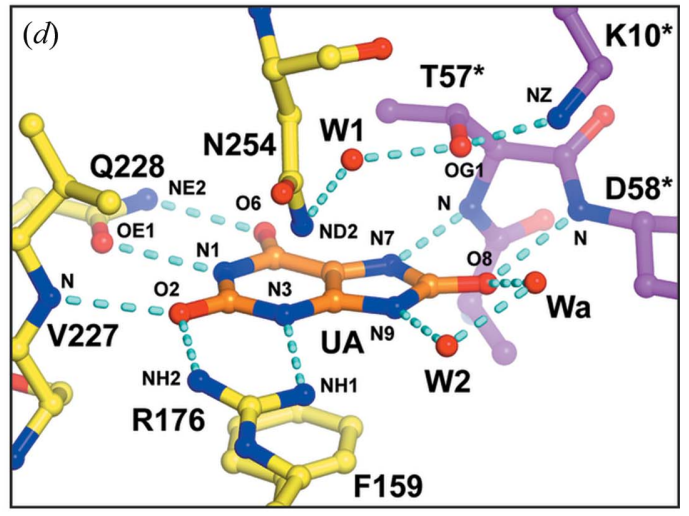

Figure 1

UOX catalysis. (a) Reaction scheme for UOX catalysis highlighting the separate oxidation and hydration steps. UOX catalyses the transformation of UA to 5-HIU. The latter is then converted to allantoin either enzymatically or non-enzymatically. $(b)$ Chemical structure of the inhibitor 8-azaxanthine (8AZA) used in this study. (c) Cartoon representation of the $\sim 137 \mathrm{kDa}$ UOX tetramer with the four protomers highlighted by different colours. Bound ligands are shown as orange sticks with their active site location marked by black rectangles. UOX binds four ligands at independent active sites each contributed by two UOX protomers. Only three are visible in the current view. (d) Stick representation of UA (orange) bound in the active site at the interface between two different UOX protomers, shown in yellow and magenta, respectively. Nitrogen and oxygen atoms are in blue and red, respectively. Water molecules (W1, W2, Wa) in close proximity to UA are represented by spheres. Hydrogen bonds are shown by cyan broken lines. Residues labelled with an asterisk indicate that they belong to a different UOX protomer. Panels $(c)$ and $(d)$ were generated using coordinates from the anaerobic UOX-UA complex (PDB entry 4d12; Bui et al., 2014). Chemical and molecular graphics representations in this work were produced with CHEMDRAW (Perkin Elmer) and PyMOL (Schrödinger, LLC) (DeLano, 2002), respectively, and assembled using Adobe Illustrator (Adobe).

the more soluble allantoin either enzymatically or nonenzymatically (Ramazzina et al., 2006). High-resolution X-ray crystallographic studies of the anaerobic complex of Aspergillus flavus UOX (hereafter simply UOX) in complex with its natural substrate UA (Bui et al., 2014) as well as with several other similar scaffolds including the 8-azaxanthine (8AZA) inhibitor employed in this study [Fig. 1(b)] (Colloc'h et al., 1997; Gabison et al., 2010; Retailleau et al., 2004), reveal that ligands bind at the interface between two protomers of the $\sim 137 \mathrm{kDa}$ UOX tetramer stabilized by several hydrogen bonds with the additional contribution of a $\pi-\pi$ stacking interaction [Figs. $1(c)$ and $1(d)$ ]. Directly above the ligand plane, a water molecule (W1) suggested to be responsible for the hydration step of catalysis (Wei et al., 2017) is coordinated by the side chains of Thr57* and Asn254 (an asterisk indicates residues belonging to the second UOX molecule contributing to the active site). A comparison with the X-ray structure of UOX in complex with the 5PIU intermediate trapped under cryo-conditions (Bui et al., 2014) shows that W1 occupies the same position of the peroxo group [Fig. S1 $(a)$ of the supporting information]. This location (the 'peroxo hole') also provides stabilization to $\mathrm{O}_{2}$ during the formation of the 5PIU intermediate (Bui et al., 2014) [Fig. S1(b)]. Small negative ions like cyanide and chloride have been visualized in the peroxo hole in the presence of intact UA under aerobic conditions (Gabison et al., 2008, 2010; Oksanen et al., 2014) offering structural support for their behaviour as competitive inhibitors.

UOX belongs to a group of intriguing cofactor-independent oxidases and oxygenases that rely on their organic substrates for $\mathrm{O}_{2}$ activation (Fetzner \& Steiner, 2010). At optimal catalytic $\mathrm{pH}(\sim 8.0)$ (Pfrimer et al., 2010), UA is a monoanion in solution and an early mechanistic proposal suggested the existence of a UOX general base dyad formed by Lys10* and Thr57* which further deprotonate UA upon binding, generating the dianion (Imhoff et al., 2003). A signature for the latter has been identified spectroscopically during catalysis (Kahn \& Tipton, 1998). As deduced by its tendency to undergo spontaneous oxidation in the gas phase (Kahn \& Tipton, 1997), the UA dianion has been proposed to transfer one electron to $\mathrm{O}_{2}$ to generate the superoxide anion $\left(\mathrm{O}_{2}^{\bullet-}\right)$. This would result in a $\left[\mathrm{UA}^{\bullet-} \cdots \mathrm{O}_{2}^{\bullet-}\right]$ pair that, following radical recombination, yields 5PIU. However, a recent theoretical study questioned the involvement of the UA dianion (Wei et al., 2017). Instead, it proposed a reaction path in which the Lys10*-Thr57* dyad abstracts the H8 proton from the UA monoanion bound in its C8-lactim form [tautomer shown in Fig. 1(a)] with a concomitant one-electron transfer to $\mathrm{O}_{2}$ resulting directly in the formation of the $\left[\mathrm{UA}^{\bullet-} \ldots \mathrm{O}_{2}^{\bullet-}\right]$ pair. The latter mechanism is supported by the neutron crystallographic structure of the UOX-UA complex solved under aerobic conditions in the presence of inhibitory chloride in the 
peroxo hole (UOX-UA-Cl- ${ }^{-}$PDB entry 4n9m; Oksanen et al., 2014) which revealed UA bound in its monoanion form deprotonated at $\mathrm{N} 3$ with a deuteron bound to O8. Deprotonation at $\mathrm{N} 3$ was also observed for 8AZA in the neutron structure of the $\mathrm{UOX}-8 \mathrm{AZA}-\mathrm{Cl}^{-}$complex (PDB entry 4n3m; Oksanen et al., 2014).

Displacement of W1 by chloride in the neutron structures currently available precludes obtaining direct information on the catalytic water and on the protonation state of its environment relevant to the hydration step of catalysis. Here, we have integrated high-resolution room-temperature neutron/ $\mathrm{X}$-ray crystallographic structural analysis with molecular dynamics (MD) simulations to study the UOX-8AZA complex in the presence of $\mathrm{W} 1$ in the peroxo hole. To maximize the signal-to-noise ratio $(\mathrm{S} / \mathrm{N})$ of the neutron diffraction data we employed perdeuterated UOX ( $\left.{ }^{\mathrm{D} U O X}\right)$ instead of relying on protium $\left({ }^{1} \mathrm{H}\right)$ /deuterium $\left({ }^{2} \mathrm{H}\right.$ or D) replacement of exchangeable hydrogens as done in previous studies on this system (Oksanen et al., 2014). Protein perdeuteration, which replaces all hydrogen atoms with deuterium, is an effective method of improving $\mathrm{S} / \mathrm{N}$ as it dramatically lowers the incoherent background while enhancing the coherent scattering signal (Fisher et al., 2014; Shu et al., 2000). In addition, perdeuteration avoids map cancellation issues, allowing all D atoms to be visualized at $\sim 2.5 \AA$ resolution or better (Blakeley \& Podjarny, 2018; Logan, 2020).

The high-resolution joint neutron/X-ray structure of ${ }^{D}$ UOX-8AZA-W1 presented here provides experimental support for a mechanism in which $\mathrm{W} 1$ attacks $\mathrm{DHU}^{\mathrm{C} 5}$ (atom C5 of DHU) with the assistance of the Lys10*- $\mathrm{NH}_{3}^{+} \cdots \mathrm{HO}-$ Thr57* dyad in which $\mathrm{Thr} 57^{* \mathrm{HG} 1}$ is central to a proton-relay system. Experiment and simulations highlight a degree of rotational freedom for the Thr57* hydroxyl group. We suggest that this helps Thr57* to fulfil a dual role of stabilizing W1 as well as acting as a proton donor to the $\mathrm{DHU}^{\mathrm{N} 7} \pi$ system to kickstart hydroxylation. Moreover, experiment and simulations also reveal an unforeseen conformational heterogeneity for Asn254 that modulates W1 stability in the peroxo hole. This might represent an active mechanism that facilitates $\mathrm{W} 1 / \mathrm{O}_{2}$ exchange during catalysis.

\section{Materials and methods}

\subsection{Perdeuterated A. flavus UOX ( $\left.{ }^{\mathrm{D} U O X}\right)$}

A. flavus urate oxidase (UOX) cDNA codon-optimized for bacterial expression was purchased from Genscript (Piscataway, NJ, USA) and cloned using the NdeI/XhoI restriction sites in a pET24b(+) expression vector (Novagen). Recombinant untagged perdeuterated UOX ( $\left.{ }^{\mathrm{D}} \mathrm{UOX}\right)$ was expressed in $E$. coli BL21 (DE3) cells. Cells were adapted for growth under deuterated conditions via a stepwise adaptation process using a minimal medium with glycerol- $\mathrm{d}_{8}$ as the carbon source. ${ }^{\mathrm{D}} \mathrm{UOX}$ was produced in a large quantity via batch-fed fermentation (Haertlein et al., 2016). ${ }^{\mathrm{D}} \mathrm{UOX}$ was purified using a multi-step protocol previously developed for protiated UOX (Bui et al., 2014). Briefly, pelleted cells were re-suspended in
$50 \mathrm{~m} M$ Tris- $\mathrm{HCl}$ (pH 8.0), $250 \mathrm{~m} M \mathrm{NaCl}$, supplemented with lysozyme, DNAse and a protease inhibitor cocktail, and lysed by sonication. Protein purification was performed using a combination of ammonium sulfate precipitation, DEAE and Resource Q ion exchange, Phenyl Sepharose hydrophobic interaction, and Superdex 75 size-exclusion chromatographic steps. After each step samples were analysed by SDS-PAGE and the purest fractions were pooled for further work. Both hydrophobic interaction and size-exclusion purification steps were carried out in the absence of $\mathrm{NaCl}$ in the buffers.

\subsection{Mass spectrometry}

Liquid chromatography electrospray ionization mass spectrometry (LC/ESI-MS) was performed on a 6210 LC-TOF spectrometer coupled to an HPLC system (Agilent Technologies). All solvents used were HPLC grade (Chromasolv, Sigma-Aldrich), trifluoroacetic acid (TFA) was from Acros Organics (puriss p.a.). Solvent A was $0.03 \%$ TFA in water, solvent B was $95 \%$ acetonitrile, $5 \%$ water and $0.03 \%$ TFA. Just before analysis protein samples were diluted under acidic denaturing conditions to a final concentration of $5 \mu M$ with solution A ( $0.03 \%$ TFA in water). Protein samples were firstly desalted on a reverse-phase C8 cartridge (Zorbax 300SB-C8, $5 \mu \mathrm{m}, 300 \mu \mathrm{m}$ ID $\times 5 \mathrm{~mm}$, Agilent Technologies) for $3 \mathrm{~min}$ at a flow rate of $50 \mu \mathrm{min}^{-1}$ with $100 \%$ solvent $\mathrm{A}$ and then eluted with $70 \%$ solvent $\mathrm{B}$ at flow rate of $50 \mu \mathrm{min}^{-1}$ for MS detection. MS acquisition was carried out in positive ion mode in the 300-3200 $\mathrm{m} / \mathrm{z}$ range. MS spectra were acquired and the data processed with the MassHunter workstation software (v.B.02.00, Agilent Technologies).

\subsection{Crystallization, neutron/X-ray data collection and structural analysis}

${ }^{\mathrm{D}} \mathrm{UOX}$ eluted from size-exclusion chromatography in $50 \mathrm{~m} M$ Tris-acetate, $30 \mathrm{~m} M$ sodium acetate at pH 8.0 was thoroughly exchanged against $50 \mathrm{~m} M$ Tris-acetate, $30 \mathrm{mM}$ sodium acetate in $\mathrm{D}_{2} \mathrm{O}, \mathrm{pD} 7.59$, before concentrating to $>20 \mathrm{mg} \mathrm{ml}^{-1}$. ${ }^{\mathrm{D}} \mathrm{UOX}-8 \mathrm{AZA}$ crystals were grown at $291 \mathrm{~K}$ using the batch crystallization method. Deuterated crystallization buffer consisted of $50 \mathrm{~m} M$ Tris-acetate, $8 \%$ PEG 8000 , $2 \mathrm{mg} \mathrm{ml}^{-1} 8 \mathrm{AZA}, \mathrm{pD}$ 7.59. Crystallization drops of $30 \mu \mathrm{l}$ total volume were prepared with protein solution and crystallization buffer in a 2:1 ratio. After $\sim 10 \mathrm{~d}$, a single crystal of approximate volume $1.5 \mathrm{~mm}^{3}(1.4 \times 1.2 \times 0.9 \mathrm{~mm})$ was mounted in a quartz capillary and sealed with wax for data collection.

Neutron quasi-Laue diffraction data to $2.10 \AA$ resolution were collected at $298 \mathrm{~K}$ on the LADI-III instrument at the Institut Laue-Langevin (ILL), Grenoble, France (Blakeley et al., 2010). Data were collected using the wavelength range 3.12-4.20 $\AA$, centred at $3.68 \AA$, and an exposure time of $1.5 \mathrm{~h}$ per image. Neutron diffraction data were indexed and integrated with the program LAUEGEN (Campbell, 1995). LSCALE (Arzt et al., 1999) was used in the wavelength normalization step, followed by data scaling and merging using SCALA (Evans, 2006), and conversion to structure factors 
Table 1

Neutron and X-ray data collection statistics.

\begin{tabular}{lll}
\hline Dataset & $\begin{array}{c}\text { DUOX-8AZA-W1 } \\
\text { neutron } \\
\text { LADI-III, ILL }\end{array}$ & $\begin{array}{l}\text { DUOX-8AZA-W1 } \\
\text { X-ray } \\
\text { BM30A, ESRF }\end{array}$ \\
Beamline & 293 & 293 \\
Temperature (K) & $3.12-4.20$ & 0.9800 \\
Wavelength $(\AA)$ & $1.5 \mathrm{~h}$ & $5 \mathrm{~s}$ \\
Exposure time per image & 11 & 240 \\
Number of images & 10 & 1 \\
Oscillation angle $\left({ }^{\circ}\right)$ & ${ }^{\circ}$ & $52.70-1.33(1.35-1.33)$ \\
Resolution range $\dagger(\mathrm{A})$ & $40.00-2.10(2.21-2.10)$ & $I 222$ \\
Space group & $I 222$ & $80.63,96.13,105.40$ \\
Cell dimensions $a, b, c(\AA)$ & $80.63,96.13,105.40$ & $93643(4505)$ \\
Unique reflections ${ }^{\dagger}$ & $19234(2357)$ & $9.2(5.3)$ \\
Overall redundancy $\dagger$ & $3.4(3.3)$ & $99.8(96.9)$ \\
Completeness $\dagger(\%)$ & $80.2(68.1)$ & $4.1(127.3)$ \\
$R_{\text {merge }} \dagger(\%)$ & $14.1(38.3)$ & $1.4(59.8)$ \\
$R_{\text {p.im. }}(I) \dagger(\%)$ & $7.9(21.5)$ & $24.4(1.2)$ \\
$\langle I / \sigma(I)\rangle \dagger$ & $5.8(2.9)$ & $100.0(46.5)$ \\
C $_{1 / 2} \dagger(\%)$ & $98.7(82.6)$ &
\end{tabular}

$\dagger$ Numbers in parentheses refer to the highest resolution bin.

using the program TRUNCATE (French \& Wilson, 1978; Winn et al., 2011). Neutron data collection statistics are given in Table 1. Subsequent to the neutron diffraction experiment, the same crystal was used for X-ray diffraction data collection at $298 \mathrm{~K}$ on the BM30A (FIP) beamline at the European Synchrotron Radiation Facility (ESRF), Grenoble, France. Data to $1.33 \AA$ resolution were indexed and integrated using the xia2 pipeline (Winter, 2010). Statistics for the X-ray dataset are also reported in Table 1.

Joint neutron/X-ray refinement was performed with the phenix.refine (Afonine et al., 2010) package of the Phenix suite (Liebschner et al., 2019) using the anisotropic treatment of ADPs for all non-hydrogen atoms. Deuterium atoms, added to the model at hydrogen positions using the READYSET program (Liebschner et al., 2019) were refined isotropically. Model fitting to X-ray and neutron maps was carried out with the package Coot (Emsley et al., 2010). Refinement statistics can be found in Table 2. The final model was deposited in the PDB (PDB entry 7a01).

\subsection{Molecular dynamics simulations}

Molecular dynamics (MD) simulations were performed with the NAMD 2.12 software (Phillips et al., 2005, 2020). Parametrization of the system, including the 8AZA ligand, was performed through CHARMM-GUI (Jo et al., 2008). The electrostatic description of the ligand was enhanced by ESP partial atomic charges, calculated separately with Gaussian09 (Frisch et al., 2013) at the B3LYP-BJD3/6-311G(d,p) level of theory (Becke, 1993; Grimme et al., 2011; McLean \& Chandler, 1980; Krishnan et al., 1980) with the CHELPG algorithm (Breneman \& Wiberg, 1990). The simulated systems were solvated in a TIP3P water box with the box size based on the dimensions of the system and giving $10 \AA$ extension in all directions. Four $\mathrm{K}^{+}$counterions were added to neutralize the system. For each system, our MD protocol consisted of the following steps: (1) energy minimization over 10000 steps using a timestep of $2 \mathrm{fs}$; (2) equilibration over $1 \mathrm{~ns}$ in the NVT
Table 2

Joint neutron/X-ray refinement statistics.

\begin{tabular}{ll}
\hline PDB code & $7 \mathrm{a} 01$ \\
Neutron $R_{\text {factor }} / R_{\text {free }}(\%)$ & $21.47 / 23.03$ \\
X-ray $R_{\text {factor }} / R_{\text {free }}(\%)$ & $10.16 / 10.93$ \\
Number of protein residues, & $295,351\left(259\right.$ as $\mathrm{D}_{2} \mathrm{O} ; 92$ as O only $)$, \\
$\quad$ solvent molecules, ligands, ions & $1(8 \mathrm{AZA}), 1\left(\mathrm{Na}^{+}\right)$ \\
Average $B$ value $\left(\AA^{2}\right)$ & $24.1,45.4,15.3,25.5$ \\
$\quad$ protein, solvent, $8 \mathrm{AZA}, \mathrm{Na}^{+}$ & \\
R.m.s. bond lengths $(\AA)$ & 0.010 \\
R.m.s. bond angles $\left({ }^{\circ}\right)$ & 1.411 \\
\hline
\end{tabular}

ensemble $(T=303.15 \mathrm{~K})$ with the RMSD of heavy atoms of the host and guest molecules constrained to their initial position using a force constant of $1 \mathrm{kcal} \mathrm{mol}^{-1} \AA^{-2}$; (3) production run in NPT ensemble with a time step of $2 \mathrm{fs}$, where the temperature and pressure were held at constant at $303.15 \mathrm{~K}$ and $1.0 \mathrm{~atm}$, respectively. Constant temperature was set by a Langevin thermostat with a collision frequency of $1 \mathrm{ps}^{-1}$, whereas the target pressure was reached using the Berendsen barostat. The Shake algorithm (Andersen, 1983) was used for bonds and angles involving hydrogen atoms. We used the particle mesh Ewald method (Darden et al., 1993) for the long-range electrostatics in combination with a cutoff of $12 \AA$ for the evaluation of the non-bonded interactions.

\subsection{Quantum mechanics/molecular mechanics calculations}

Quantum mechanics/molecular mechanics (QM/MM) calculations, including geometry minimizations and molecular dynamics simulations, were performed with CHARMM molecular mechanics simulation software (Brooks et al., 2009). Parametrization of the system was performed through CHARMM-GUI (Jo et al., 2008). A cutoff distance of $12 \AA$ was used for the Lennard-Jones and electrostatic interactions. In order to keep smooth transition to zero, shifting was applied to the pairwise interactions over $10 \AA$ distances. Residues further than $25 \AA$ from the ligand were deleted from the structures. We applied constraints on the atoms lying further than $15 \AA$ from a ligand to keep them at their original positions. These geometry restrictions were defined for the starting structure and kept unaltered through the calculations. The forces acting on the QM region of the model were calculated externally with the $Q$-Chem 4.3 software suite (Shao et al., 2015), which also involved the surrounding atoms as point charges. DFT calculations were performed at the B $3 \mathrm{LYP} / 6-31+\mathrm{G}^{*}$ level of theory. For geometry minimizations a limit of 1000 steps and a threshold for the RMSD of the gradient of $0.005 \mathrm{kcal} \mathrm{mol}^{-1}$ was applied. The connection between the QM and the MM regions was maintained with hydrogen link atoms.

\section{Results}

3.1. Perdeuterated $A$. flavus UOX ( ${ }^{\mathrm{D} U O X}$ ) for neutron crystallography

A. flavus UOX expressed recombinantly in Saccharomyces cerevisiae is a therapeutic commercial product of SanofiAventis under the brand name Fasturtec. Several high- 
resolution structural studies on this enzyme relied on protein material kindly gifted by the company (Gabison et al., 2010; Oksanen et al., 2014; Retailleau et al., 2004). To circumvent this limitation we previously set up a heterologous expression system in E. coli (Bui et al., 2014). Using codon-optimized cDNA, untagged UOX can be expressed in good quantities and purified to homogeneity allowing us to obtain crystals that diffract X-rays to atomic resolution (Bui et al., 2014). Bacterial expression of UOX from other organisms has also been reported enabling X-ray crystallographic studies to be performed, albeit at lower resolution (Hibi et al., 2016; Marchetti et al., 2016; Imhoff et al., 2003).

As neutron crystallographic studies benefit substantially from data collection on fully deuterated crystals we took advantage of the D-LAB facility (ILL, Grenoble, France) to produce perdeuterated UOX ( $\left.{ }^{\mathrm{D}} \mathrm{UOX}\right)$ using our expression construct. Stepwise adaptation of E. coli to $100 \% \mathrm{D}_{2} \mathrm{O}$ and the use of deuterated glycerol as a carbon source allowed us to obtain high levels of ${ }^{\mathrm{D}} \mathrm{UOX}$ after optimization of fermentation conditions (Haertlein et al., 2016). Purification of ${ }^{\mathrm{D}} \mathrm{UOX}$ mirrored the strategy we established previously for (protiated) UOX affording more than $50 \mathrm{mg}$ of pure ${ }^{\mathrm{D}} \mathrm{UOX}$ per litre of culture [Fig. 2(a)]. The degree of deuteration was estimated by MS at $>99 \%$ [Figs. 2(b) and 2(c)].

\subsection{Joint neutron/X-ray structure of the ${ }^{\mathrm{D} U O X-8 A Z A-W 1}$ complex}

A single crystal (volume $\simeq 1.5 \mathrm{~mm}^{3}$ ) of ${ }^{\mathrm{D}} \mathrm{UOX}$ in complex with 8AZA obtained under chloride-free conditions was
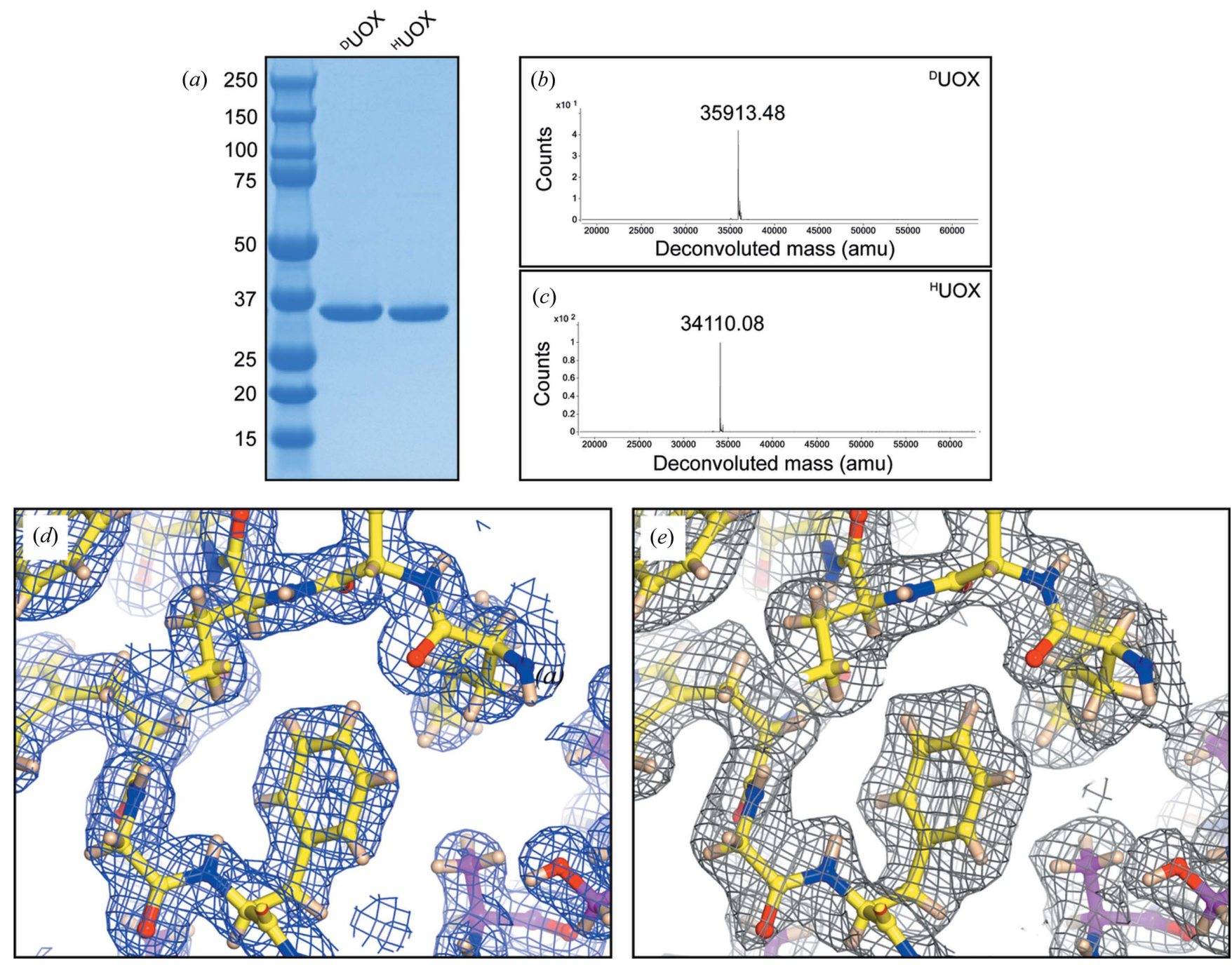

Figure 2

${ }^{\mathrm{D}}$ UOX and examples of electron and neutron density maps for the ${ }^{\mathrm{D}} \mathrm{UOX}-8 \mathrm{AZA}-\mathrm{W} 1$ complex. (a) SDS-PAGE analysis of purified ${ }^{\mathrm{D}} \mathrm{UOX}$ and ${ }^{\mathrm{H}} \mathrm{UOX}$ (protiated, for comparison) samples. Protein markers are on the left-hand side lane with their molecular weights indicated. (b), $(c)$ ESI-MS analysis of purified $(b){ }^{\mathrm{D}} \mathrm{UOX}$ and $(c){ }^{\mathrm{H}} \mathrm{UOX}$, showing a mass difference of 1803 a.m.u. As the calculated mass difference (assuming complete deuteration) is 1820 a.m.u., this corresponds to $\sim 99.1 \%$ deuterium incorporation in the ${ }^{\mathrm{D}} \mathrm{UOX}$ sample. $(d)$, $(e)$ Representative examples of $2 m F_{\mathrm{o}}-D F_{\mathrm{c}}(d)$ electron density and $(e)$ neutron maps contoured at the $1.0 \sigma$ level. X-ray and neutron data extend to 1.33 and $2.10 \AA$, respectively. As in Fig. $1(c)$, residues shown in yellow and magenta belong to different UOX protomers. Nitrogen, oxygen and deuterium atoms are shown in blue, red and wheat, respectively. The use of perdeuterated UOX provides neutron maps essentially free from cancellation effects affording clear visualization of both non-exchangeable and exchangeable hydrogens. 
utilized to collect sequentially room-temperature neutron and $\mathrm{X}$-ray diffraction data at resolutions of 2.10 and $1.33 \AA$, respectively. Data collection statistics are given in Table 1. As the crystal was both perdeuterated and had a large volume, relatively short exposure times could be used for neutron data collection, allowing the complete dataset to be collected in only $16.5 \mathrm{~h}$ at the LADI-III beamline at the ILL (Blakeley et al., 2010). Typically, neutron data collections take several days (Blakeley \& Podjarny, 2018) and so the data collection for our study described here represents (as far as we are aware) the fastest neutron data collection for a protein with a relatively large unit cell. For X-ray data collection we did not attempt to measure data at the highest possible resolution. Instead, we opted to collect a complete dataset with negligible radiation damage. Electron density maps display none of the specific signatures typically associated with radiation damage, such as decarboxylation of acidic residues (Ravelli \& McSweeney, 2000; Weik et al., 2000). In addition, neutron and X-ray datasets are isomorphous ruling out any obvious unit-cell expansion during X-ray data collection, a global indicator of radiation damage (Garman, 2010).

As typically observed for protiated UOX crystals, the ${ }^{D}$ UOX-8AZA-W1 complex crystallizes in the orthorhombic space group I222. The asymmetric unit contains a single ${ }^{D}$ UOX chain that generates the biological tetramer of $D 2$ symmetry following the application of crystallographic symmetry operations. Joint neutron/X-ray refinement delivered a final model characterized by $R / R_{\text {free }}$ values of $21.47 \% /$ $23.03 \%$ and $10.16 \% / 10.93 \%$ for neutron and X-ray data, respectively. ${ }^{\mathrm{D}} \mathrm{UOX}$ residues are visible for residues 1-295, whereas the six $\mathrm{C}$-terminal residues are flexible. In addition to the 8AZA ligand, 259 solvent molecules are modelled as $\mathrm{D}_{2} \mathrm{O}$ and 92 additional ones are modelled as oxygen atoms only owing to rotational disorder. Refinement statistics are summarized in Table 2. The use of perdeuterated UOX results in nuclear scattering length density free from protium-induced cancellation effects which allows the visualization of both exchangeable and non-exchangeable hydrogens. Representative examples of the excellent quality of X-ray and neutron maps are given in Figs. 2(d), 2(e) and S2.

A superposition of the final room-temperature ${ }^{\mathrm{D}} \mathrm{UOX}-$ 8AZA-W1 model with that of the $1.75 \AA$ resolution UOX8AZA-W1 X-ray structure solved at $4^{\circ} \mathrm{C}(277 \mathrm{~K})$ (PDB entry 1r51; Retailleau et al., 2004) or with that of H/D-exchanged $1.1 \AA$ resolution ${ }^{\mathrm{H} / \mathrm{D}} \mathrm{UOX}-8 \mathrm{AZA}-\mathrm{Cl}^{-} \mathrm{X}$-ray structure solved at $100 \mathrm{~K}$ (PDB entry 4n9v; Oksanen et al., 2014) reveals essentially no differences, with RMSD values of 0.18 and $0.22 \AA$, respectively, for all common main-chain atoms. Thus, in line with what has been reported for other proteins (Koruza et al., 2019), partial or complete deuterium-labelling does not induce major structural changes in UOX.

\subsection{AZA and W1}

As observed in previous UOX complexes (Colloc'h et al., 1997, 2007; Retailleau et al., 2004; Oksanen et al., 2014), 8AZA binds in the active site at the interface between two UOX protomers with direct hydrogen-bond stabilizing contributions from Thr57*, Asp58*, Arg176, Val227 and Gln228, while residues Tyr8*, Ile54*, Ala56*, Phe159, Leu170 and Ser226 further line the binding pocket with Phe159 engaged in $\pi-\pi$ stacking with the pyrimidine ring of 8AZA [Fig. 3(a)]. We observe dual conformations for the side chains of Tyr8* and Ile 54*, as well as for Ile288 located directly above Gln228.

8AZA binds as the N3 monoanion with clear nuclear scattering length density for deuterons linked to $\mathrm{N} 1$ and $\mathrm{N} 9$. Although nuclear scattering length density in omit maps appeared somewhat stronger for the hydrogen bound to N1, occupancy refinement gives unitary values for both deuterons. A water molecule (W2) forms a strong hydrogen bond with $8 \mathrm{AZA}^{\mathrm{D} 9}\left(8 \mathrm{AZA}^{\mathrm{D} 9} \cdots \mathrm{W} 2^{\mathrm{O}}=1.84 \AA\right)$, though there is no evidence for a solvent molecule interacting with $8 \mathrm{AZA}^{\mathrm{N} 8}$ as seen in the anaerobic complexes with UA and its 9-methyl derivative (9-MUA), both of which can react with $\mathrm{O}_{2}$ to form C5-peroxides (Bui et al., 2014).

W1 is visualized in the electrostatically positive peroxo hole above the 8AZA plane and with its oxygen atom facing Thr57* [Fig. 3(b)]. Electron density maps clearly define the position of the $\mathrm{W} 1$ oxygen $\left(\mathrm{W} 1^{\mathrm{O}}\right)$, whereas omit neutron maps calculated by modelling $\mathrm{W} 1$ as $\mathrm{W} 1{ }^{\mathrm{O}}$ only show elongated positive difference density next to the oxygen, which is consistent with the presence of two deuterium atoms [Fig. $3(c)$ ]. In the final model $\mathrm{W} 1$ refines to an overall occupancy of 0.93. It is sandwiched between Thr57* and Asn254 with its plane oriented at $\sim 45^{\circ}$ with respect to that of 8AZA with its $\mathrm{O}-\mathrm{D} 1$ bond almost parallel to it and directed into a small cavity lined by 8 AZA, Lys10*, Thr57*, Asn254 and His 256 [Fig. 3(d)]. $\mathrm{W} 1{ }^{\mathrm{O}}$ is hydrogen bonded to Thr57*DG1 at a distance of $2.16 \AA$. Similar distances $(2.23-2.25 \AA$ ) are also observed between $\mathrm{W} 1^{\mathrm{O}}$ and the amide deuterons of Asn254, which, similar to other residues lining the active site (Tyr8*, Ile54*, Ile288), also exhibit alternative conformations. The visualization of W1 hydrogens allows us to also define an unanticipated $\mathrm{O}-\mathrm{H} \cdots \pi$ interaction with the ligand. Following the classical parametrization for this type of bond (Steiner \& Koellner, 2001), which uses the distance $\left(d_{\mathrm{O} \cdots m}\right)$ between the donor atom $(\mathrm{O})$ and the midpoint of the ring $(m)$, the $\omega(\mathrm{O})$ angle between the $\mathrm{O} \cdots m$ line and the ring normal as well as the $\mathrm{O}-\mathrm{H} \cdots m$ angle [Fig. 3(d)], we find values of $d_{\mathrm{O} \cdots m}=3.64 \AA, \omega(\mathrm{O})=23.8^{\circ}$ and $\angle(\mathrm{O}-\mathrm{H} \cdots m)=141^{\circ}$ that are consistent with those most commonly observed for the peptide $n \rightarrow(n-2) \mathrm{N}-\mathrm{H} \cdots \pi$ interaction for which there are abundant data in proteins (Steiner \& Koellner, 2001).

\subsection{Lys 10*-Thr57* dyad}

The active-site dyad formed by Lys10*-Thr57* has been implicated in various stages of the catalytic cycle (Gabison et al., 2010; Imhoff et al., 2003; Wei et al., 2017), thus its protonation state was carefully investigated. While difference neutron maps for Lys10* showed a clear 'tri-lobe' nuclear density distribution around $\mathrm{NZ}$ that is consistent with a positively charged (Lys10*-ND ${ }_{3}^{+}$) group [Fig. 4(a)], the identification of the protonation state for Thr57* was not so 

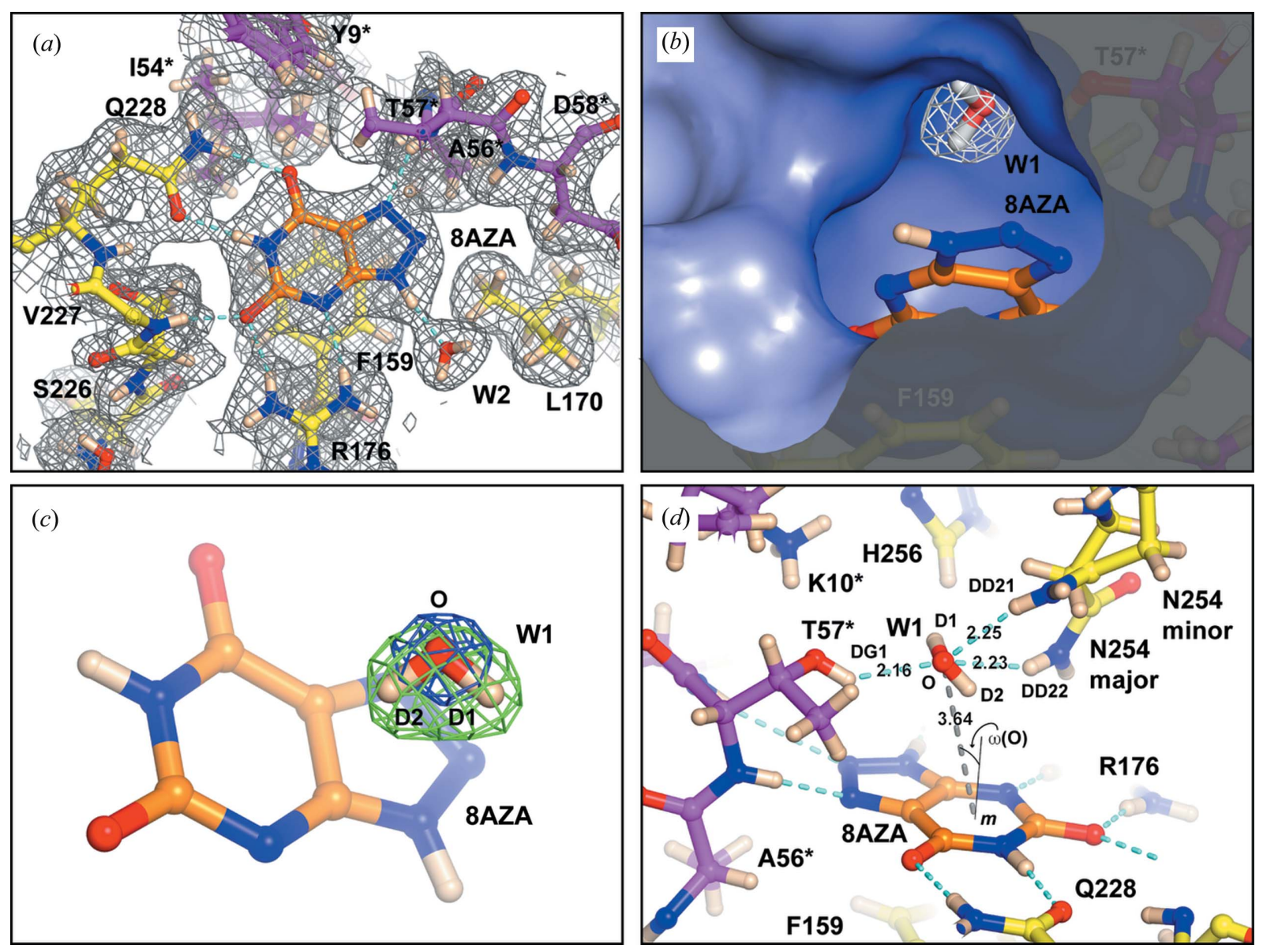

Figure 3

8AZA and W1. (a) 8AZA monoanion (orange) bound in the active site viewed from the peroxo hole. $2 m F_{\mathrm{o}}-D F_{\mathrm{c}}$ neutron density map is shown in grey at the $1.0 \sigma$ level for active site residues. Amino acids shown in yellow and magenta belong to different UOX protomers. Nitrogen, oxygen and deuterium atoms are shown in blue, red and wheat, respectively. Hydrogen bonds are shown as cyan broken lines. Residues labelled with an asterisk indicate that they belong to a different UOX protomer. $(b)$ Sliced-surface view of W1 bound in the peroxo hole located above the flat binding pocket occupied by 8AZA. The molecular surface is coloured according to the electrostatic potential with positive potential shown as shades of blue. $2 m F_{\mathrm{o}}-D F_{\mathrm{c}}$ neutron density map for $\mathrm{W} 1$ is shown at the $1.5 \sigma$ level. $(c) \mathrm{W} 1$ is present as a neutral $\mathrm{H}_{2} \mathrm{O}$ molecule. $2 m F_{\mathrm{o}}-D F_{\mathrm{c}}$ electron density map shown in blue at the $3.0 \sigma$ level clearly define the $\mathrm{W} 1^{\mathrm{O}}$ position. An omit $m F_{\mathrm{o}}-D F_{\mathrm{c}}$ neutron map calculated only with $\mathrm{W} 1^{\mathrm{O}}$ contribution indicates the presence of two deuterons $(\mathrm{D} 1, \mathrm{D} 2)$ as suggested by the elongated positive density (in green at the $+3.0 \sigma$ level) next to the oxygen atom. $(d)$ W1 is sandwiched between Thr57* and Asn254. The latter is modelled in two conformations that refine at 0.8 (major) and 0.2 (minor) occupancy, respectively. W1 is oriented such that its D2 atom forms an $\mathrm{O}-\mathrm{H} \cdots \pi$ hydrogen bond with 8AZA. Useful parameters to describe this type of interaction are the O- $m$ distance (broken grey line), where $m$ is the midpoint of the six-membered pyrimidine ring, the $\omega(\mathrm{O})$ angle between the $\mathrm{O} \cdots m$ line and the ring normal (thin continuous black line), as well as the $\mathrm{O}-\mathrm{D} 2 \cdots m$ angle (Steiner \& Koellner, 2001). These values are $3.64 \AA$ \&, $23.8^{\circ}$ and $141^{\circ}$, respectively.

straightforward. Difference neutron maps did not provide evidence for a positive peak adjacent to $\mathrm{Thr} 57^{* \mathrm{OG} 1}$ at the $+3.0 \sigma$ level but positive density that can be attributed to DG1 was seen at the $+2.0 \sigma$ level [Fig. 4(a)]. As neutron omit maps offered only a mild suggestion for the presence of a deuteron bound to Thr $57^{* \mathrm{OG} 1}$ and difference map interpretation at low threshold levels need to be considered very carefully, we decided to investigate the unlikely possibility of a Lys $10^{*}-$ $\mathrm{NH}_{3}^{+} \ldots \mathrm{O}^{-}-\mathrm{Thr} 57^{*}$ ionic pair using theoretical methods. However, this scenario was quickly ruled out as already during the first few frames of QM/MM minimization (order of a few femtoseconds) a spontaneous proton transfer occurs from the Lys10* amine to the Thr57* hydroxylate resulting in the establishment of a Lys10*- $\mathrm{NH}_{2} \cdots \mathrm{HO}-\mathrm{Thr} 57^{*}$ hydrogen bond (Fig. S3). This strongly argues against the deprotonation of Thr57*.
We then considered the possibility that Thr57* is in the neutral state and that the lack of clear density for DG1 in neutron difference maps can be attributed to positional heterogeneity which cannot be interpreted fully at the resolution of our neutron diffraction data $(2.10 \AA)$. To further explore this, we calculated the distribution of the CA-CBOG1-HG1 torsion angle during a $100 \mathrm{~ns}$ classical MD simulation. As shown in Fig. 4(b), this dihedral exhibits a rather broad asymmetric profile ranging from -10 to $-190^{\circ}$ with a maximum at around $-72^{\circ}$, resulting in the OG1-HG1 bond pointing 'down' towards $8 \mathrm{AZA}$, almost perpendicular to it. A smaller 'shoulder' is also seen around $-135^{\circ}$, with OG1-HG1 parallel to 8AZA. We therefore modelled a deuteron atom bound to $\mathrm{Thr} 57^{* \mathrm{OG} 1}$ as suggested by omit neutron maps. Occupancy refinement for this atom gives a value of 0.78 . In the final model the CA-CB-OG1-DG1 torsion angle displays 

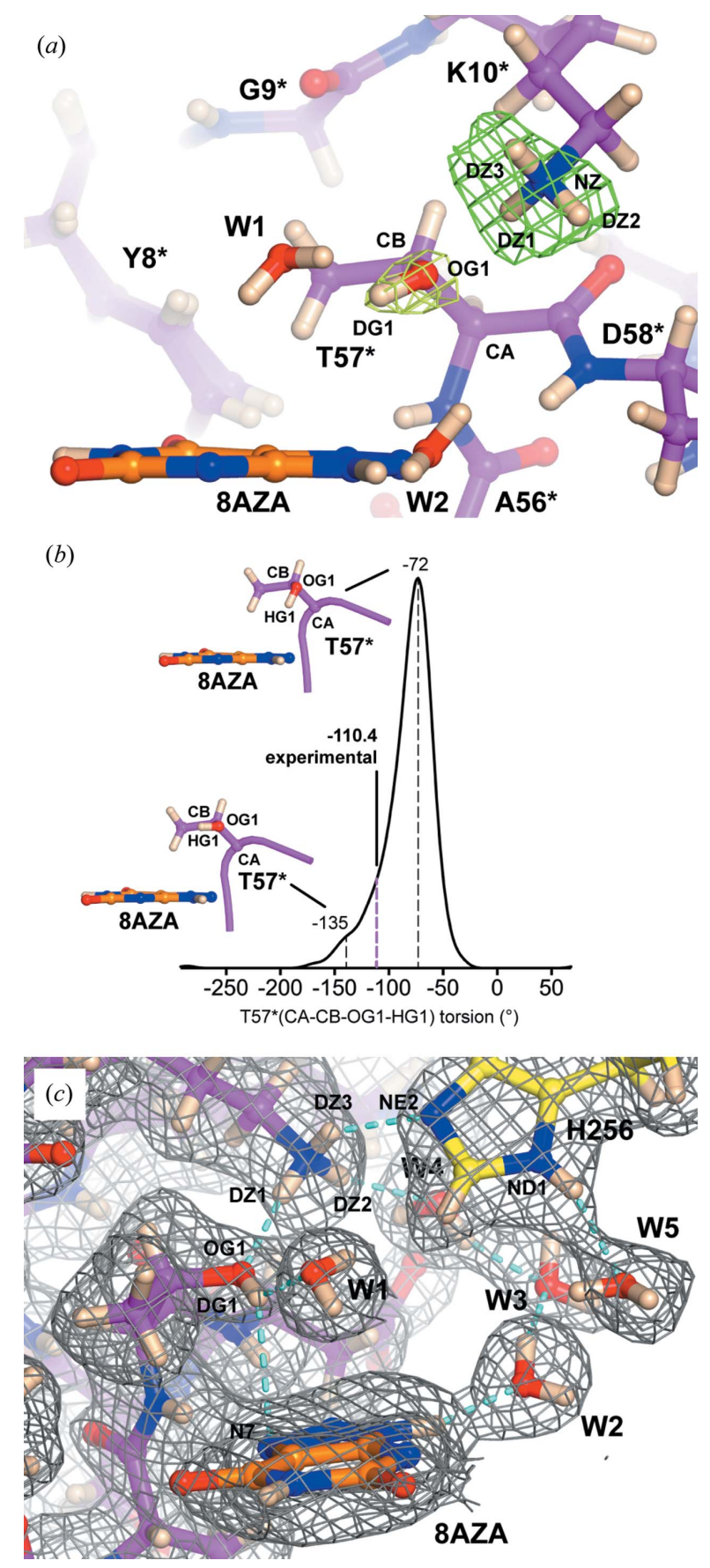

Figure 4

Lys10*-Thr57* dyad. (a) Stick representation of a portion of the active site highlighting the Lys10*-Thr57* dyad. Difference neutron density calculated in the absence of deuterons bound to Lys $10^{* \mathrm{NZ}}$ and Thr57*OG1 is shown at the $+3.0 \sigma$ (green) and $+2.0 \sigma$ (lemon) levels, respectively. No significant peak was observed near Thr $577^{\circ \mathrm{OG} 1}$ at the $+3.0 \sigma$ level. $(b)$ Normalized probability distribution of the Thr57* (CA-CB-OG1-HG1) torsion angle during a $100 \mathrm{~ns}$ classical MD simulation. Stick representations highlight the structures at $-72^{\circ}$ (OG1-HG1 bond pointing toward the triazole ring of $8 \mathrm{AZA}$ ) and $-135^{\circ}$ angles (OG1-HG1 bond parallel to the 8 AZA plane). The broken magenta line at $-110.4^{\circ}$ indicates the torsion angle in the final structure. (c) Protonation state in the active site. A strong hydrogen bond is formed between Lys10*DZ1 and Thr57*OG1 $\left(1.97 \AA\right.$ ) while Thr57* ${ }^{\mathrm{DG} 1}$ is engaged in an $\mathrm{O}-\mathrm{H} \cdots \pi$ interaction $(2.77 \AA)$ with $\mathrm{N} 7$ of the $8 \mathrm{AZA}$ triazole ring. A chain of water molecules (W2, W3, W4) connects 8AZA to the dyad. His256 is neutral with its hydrogen located on ND1 which is hydrogen bonded to W5. Cyan broken lines represent hydrogen bonds. Residue Asn254 has been omitted for clarity. a value of $-110.4^{\circ}$ resulting in a slight downward orientation of the OG1-DG1 bond towards the ligand plane with the deuteron at $2.77 \AA$ from $8 \mathrm{AZA}^{\mathrm{N} 7}$, thus indicating another $\mathrm{O}-$ $\mathrm{H} \cdots \pi$ interaction [Fig. 4(c)]. All deuterons bound to Lys $10 * \mathrm{NZ}$ also refine to high occupancy $(>0.90)$ with a hydrogen bond between Lys10*DZ1 and Thr57*OG1 at a distance of $1.97 \AA$. Lys10* is in turn hydrogen bonded to His256. The latter is neutral, with its hydrogen residing on ND1. As a result, His $256^{\text {NE2 }}$ accepts a hydrogen bond from the Lys $10^{* \mathrm{DZ} 3}$, positioned at a distance of $2.24 \AA$. Lys $10^{* \mathrm{DZ} 2}$ is hydrogen bonded to water W4 that, together with W5 and W2, completes a chain of solvent molecules connecting the Lys10*-Thr57* dyad to $\mathrm{AZA}^{\mathrm{D} 9}$. Overall, experimental data and theoretical calculations are consistent with the existence of a Lys10*-ND ${ }_{3}^{+} \ldots$ DO-Thr57* dyad in which the Thr57*OG1-DG1 bond is directed towards $8 \mathrm{AZA}$, on average.

\subsection{Heterogeneity of Asn254 and its flanking residues}

During crystallographic refinement, inspection of nearatomic resolution X-ray difference maps showed a pattern of positive and negative peaks for the tripeptide linker Pro253Lys 255 connecting the $\beta 7$ and $\beta 7^{\prime}$ strands. This indicated the existence of an alternative conformation in addition to the main one typically observed, which we could model [Fig. 5(a)]. Occupancy refinement for this short stretch that hosts Asn254 suggests an approximate 75:25 ratio for the major [yellow in Fig. 5(a)] and minor (dark grey) conformations. In the latter, Pro253 is shifted towards $\beta 8$ resulting in a movement of Asn254 in the opposite direction. This leads to an Asn254 ${ }^{\text {CA }}$ displacement of $\sim 1.4 \AA$ and the consequent movement of its side chain that nevertheless remains at hydrogen-bond distance from W1. Modelling of this region in an alternative conformation made a residual peak more obvious in $m F_{\mathrm{o}}-D F_{\mathrm{c}}$ electron density maps at the $+4.0 \sigma$ level $\left(\sim 0.25 \mathrm{e}^{-} \AA^{-3}\right)$ near the amide group of Asn254 in its major conformation (Fig. S4). We interpreted this peak as a lowoccupancy water molecule (oxygen atom only, refined occupancy $=0.21$ ). Inclusion of this solvent molecule in the model fully accounted for the positive difference density. Moreover, we calculated $2 m F_{\mathrm{o}}-D F_{\mathrm{c}}$ feature enhanced maps (FEM) that can strengthen weak signals, if present, and can reduce model bias and noise (Afonine et al., 2015). The FEM map for this region shows clearly the alternative conformation for Pro253Lys255 peptide as well as a 'bulge' on the side of the amide plane that supports our modelling of this low-occupancy water (W') [Fig. 5(b)].

To further validate our experimental observation of flexibility for this region we looked at the distribution of Asn254 torsion angles using MD simulations [Fig. 5(c)]. Two independent $100 \mathrm{~ns}$ simulations were carried out using a UOX dimer model (thus allowing the analysis of two active sites in each run) (Fig. S5) with the Pro253-Lys255 stretch either in the major or minor conformation. The initial $25 \mathrm{~ns}$ of each simulation were removed from the analysis to avoid bias caused by system conditioning. As shown in Fig. 5(c), the MD simulations allow us to define four main cluster areas (green, 


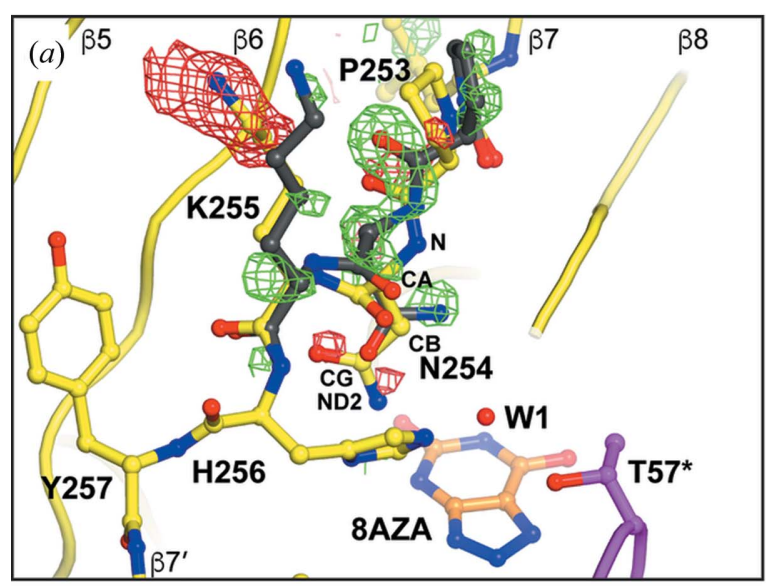

(c)
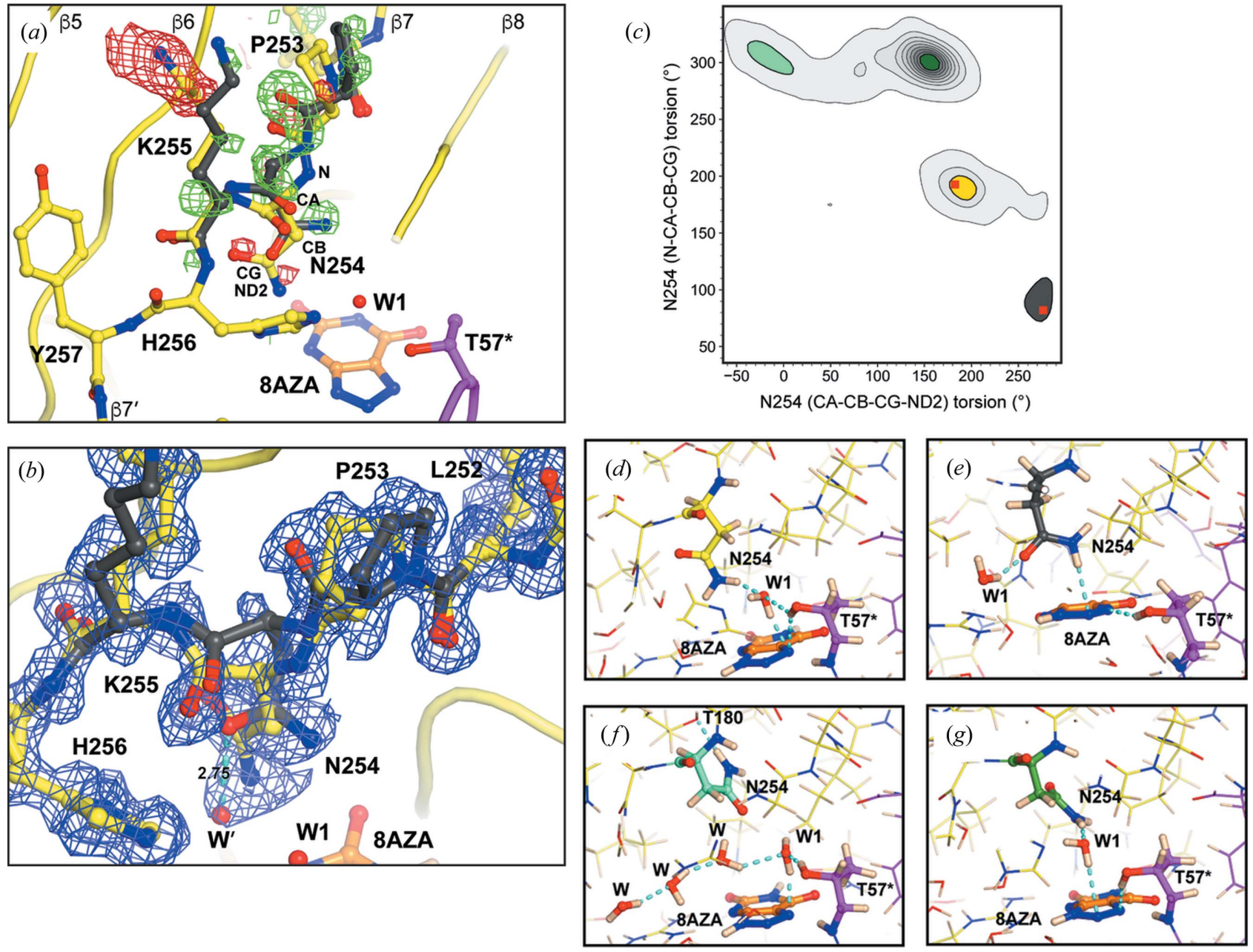

Figure 5

Asn254 heterogeneity. (a) Close-up of the $\beta 5-\beta 8$ region highlighting an alternative conformation for the Pro253-Lys255 tripeptide. Strands are shown as tubes and the stretch connecting $\beta 7$ to $\beta 7^{\prime}$ as sticks. Deuterium atoms have been omitted for clarity. The main conformation for the Pro253-Lys 255 tripeptide is shown in yellow and the second conformation is represented in dark grey for reference. Difference $m F_{\mathrm{o}}-D F_{\mathrm{c}}$ electron density maps at the $+3.0 \sigma$ and $-3.0 \sigma$ levels calculated after refinement without the minor conformation included in the model are shown in green and red, respectively. The alternative conformation stretch explains the residual density well. $(b)$ Feature-enhanced $2 m F_{\mathrm{o}}-D F_{\mathrm{c}}$ map (FEM) for the Pro253-Lys255 tripeptide and neighbouring residues. Colour codes are the same as in $(a)$. The solvent molecule $\mathrm{W}^{\prime}$ is hydrogen bonded to the oxygen atom of the Asn254 amide in the minor conformation. (c) 2D contour plot for Asn254 torsion angles from MD simulations highlighting four main clusters represented by different colours (green, yellow, aqua and dark grey). Red squares within the yellow and dark grey clusters identify experimental torsion angles for the major (179 ${ }^{\circ}$, $\left.-192^{\circ}\right)$ and minor $\left(272^{\circ}, 81^{\circ}\right)$ Asn 254 conformations, respectively. $(d)-(g)$ Representative structures of each torsion angle cluster identified by the simulations: $(d)$ yellow, $(e)$ dark grey, $(f)$ aqua, $(g)$ green. 8AZA, Thr57*, Asn254, W1 and other water molecules at hydrogen-bond distance are shown as sticks. Asn254 is colour-coded according to the cluster to which it belongs. Hydrogen bonds are shown by broken cyan lines.

yellow, aqua, dark grey) in the (CA-CB-CG-ND2)-(N-CACB-CG) 2D contour plot. The cluster highlighted in yellow is representative of the main conformation seen in the crystal [red square at $179^{\circ}, 192^{\circ}$ in Fig. $5(c)$ ] and confirms that this rotamer is sampled often during the simulation. A snapshot from the simulation illustrative of this cluster is given in Fig. $5(d)$ and shows an arrangement similar to that seen in the crystal. The dark grey cluster representing the minor crystallographic conformation (red square at $272^{\circ}, 81^{\circ}$ ) is also occasionally visited, thus lending support to our structural observation. In many structures of this cluster W1 moves away from the peroxo hole with the hydrogen of the Asn254 amide replacing $\mathrm{W} 1$ in an $\mathrm{N}-\mathrm{H} \cdots \pi$ interaction with 8AZA [Fig. $5(e)]$. This novel $\mathrm{W} 1$ position appears consistent with that of that of the low-occupancy $\mathrm{W}^{\prime}$ in our model.
The simulations also reveal additional torsion angles frequently adopted by Asn 254 that define almost a continuum (aqua and green clusters). Representative structures are shown in Figs. $5(f)$, and $5(g)$, respectively. Structures belonging to the aqua cluster display the Asn254 side-chain carbonyl group pointing towards the peroxo hole typically resulting in the displacement of $\mathrm{W} 1$ and the establishment of a solvent chain organized above the ligand [Fig. 5(f)]. The transition from the aqua to the green cluster involves a $90^{\circ}$ rotation of the amide plane resulting in the carbonyl 'pointing away' from the peroxo hole and thus establishing a hydrogen bond between one of the HD hydrogens and W1 [Fig. 4(g)]. Taken together, experiment and theory indicate that Asn254 is rather dynamic and able to explore a range of conformations. 

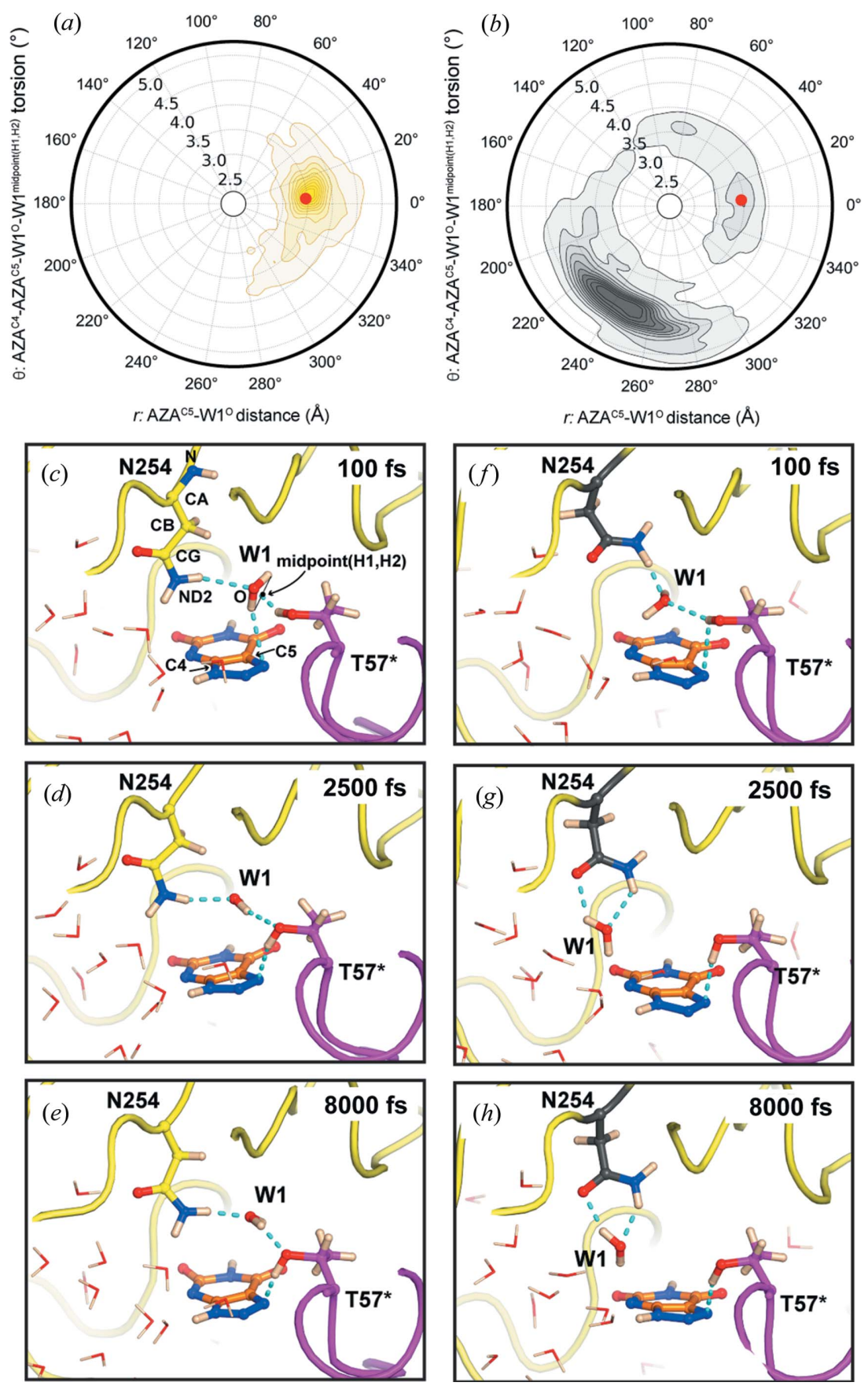

Figure 6

The W1 position is coupled to Asn254 conformations. (a) Radial $(r, \theta)$ plot for the QM/MM$\mathrm{MD}$ simulation with Asn254 in the major conformation. The distance $\mathrm{AZA}{ }^{\mathrm{C}}-\mathrm{W} 1^{\mathrm{O}}$ is shown along $r$ with the $\mathrm{AZA}^{\mathrm{C} 4}-\mathrm{AZA}^{\mathrm{C} 5}-\mathrm{W} 1^{\mathrm{O}}-\mathrm{W} 1^{\text {midpoint(}(\mathrm{H} 1, \mathrm{H} 2)}$ torsion angle as $\theta$. The red circle indicates values for these parameters derived from the crystal structure. W1 is relatively stable during the simulation at values close to experimental ones. (b) Following $(a)$, but for the QM/MM-MD simulation with Asn254 in the minor conformation. In contrast to what is shown in $(a)$, when Asn254 is in the minor conformation W1 moves to greater distances from C5 (maximum at $4.2 \AA$ ) exhibiting a broader distribution of different $\left(225-255^{\circ}\right.$ ) dihedral angles. $(c)-(h)$ Cartoon snapshots from the simulations. $(c)-(e)$ are from the simulation starting with the Pro253-Lys255 region in the major crystallographic conformation; $(f)-(h)$ are from the simulation starting with the Pro253-Lys255 region in the minor crystallographic conformation. Thr57*, Asn254, W1 and 8AZA are in stick form with the protein backbone shown as a tube. Other water molecules are shown as lines. Broken cyan lines indicate hydrogen bonds. The minor Asn 254 conformation facilitates W1 removal from the peroxo hole by stabilizing it in a new position toward the solvent-exposed of the active site at longer distance from C5. Supplementary Movies S1 and S2 are provided for the QM/MM-MD simulations.

\subsection{Asn254-W1 coupling}

Together with Thr57*, Asn254 is involved in W1 binding and also in the stabilization of $\mathrm{O}_{2}$ and 5PIU during the oxidative stage of catalysis (Bui et al., 2014). As both $\mathrm{H}_{2} \mathrm{O}$ and $\mathrm{O}_{2}$ must access the peroxo hole during the reaction cycle we considered the possiblity that Asn254 dynamics might offer a mechanism to modulate W1 stability at this location. To investigate this further, we performed QM/ MM MD simulations. Similar to the approach employed in our classical MD simulations, we performed independent 8 ps-long runs using initial structures in which the Pro253-Lys255 region was either in the major or minor conformation. Asn254 torsion angles remain stable during the simulations indicating energetic minima (Fig. S6). We then inspected W1 movements using the $\mathrm{AZA}^{\mathrm{C} 5}-\mathrm{W} 1^{\mathrm{O}}$ distance and the $\mathrm{AZA}^{\mathrm{C} 4}-\mathrm{AZA}^{\mathrm{C} 5}-\mathrm{W} 1{ }^{\mathrm{O}}-\mathrm{W} 1^{\text {average }(\mathrm{H} 1, \mathrm{H} 2)}$ dihedral angle as coordinate parameters. For the major conformation [Fig. 6(a)], W1 mostly explores distances between 3.1 and $4.0 \AA$ with a maximum at $3.6 \AA$ and a narrow dihedral distribution centred around $10^{\circ}$. This is in excellent agreement with the experimental values in our structure $\left(3.47 \AA, 6^{\circ}\right)$. The snapshots at different time points in Figs. 6(c), $6(d)$ and 6(e) provide further visual confirmation that $\mathrm{W} 1$ is relatively stable within the peroxo hole when Asn254 is in the major conformation (see Supplementary Movie S1 in the supporting information). The situation is different for the minor conformation [Fig. $6(b)]$. Under these conditions W1 moves at longer distances from $\mathrm{AZA}^{\mathrm{C} 5}$ (maximum at 4.2-4.4 $\AA$ ) exhibiting a broader distribution of different dihedral angles $\left(225-255^{\circ}\right)$. This is the result of W1 leaving the peroxo hole (we observe this after $\sim 500 \mathrm{fs}$ ) stabilized by the amide group of Asn254 as seen in the snapshots in Figs. 6(f) 6(g) and 6(h) (see Supplementary Movie S2). In our final crystallographic model $\mathrm{W}^{\prime}$ refines at a distance of $4.4 \AA$ from $\mathrm{AZA}^{\mathrm{C} 5}$ and at hydrogen-bonding distance of $2.75 \AA$ from Asn $254^{\mathrm{OD} 1}$ (minor). Taken together, experiment and theory (both standard MD and QM/MM-MD) are in excellent agreement and support the view that the minor crystallographic conformation favours the displacement of $\mathrm{W} 1$ from the peroxo hole.

\section{Discussion}

The synergistic use of experimental and theoretical approaches provides a powerful 
way to gain insight into the mechanisms of enzyme catalysis (Bui \& Steiner, 2016; Huggins et al., 2019). Here, we have integrated high-resolution room-temperature neutron/X-ray crystallographic analysis with biomolecular simulations to study co-factor-independent UOX in complex with its competitive inhibitor 8AZA in the presence of the catalytic water molecule $\mathrm{W} 1$ bound in the peroxo hole.

Our room-temperature analysis has uncovered structural heterogeneity for the Pro253-Lys255 tripeptide. This involves residue Asn254 which interacts directly with W1. Highresolution crystallographic studies at room temperature are extremely valuable in the detection of functional multiconformers or rare states in enzymes restricted under cryogenic conditions (Fraser et al., 2011). Early studies involving crystals of myoglobin (Frauenfelder et al., 1987, 1979) and ribonuclease (Rasmussen et al., 1992; Tilton et al., 1992) have shown that conformational distributions are restricted at low temperatures and, for human proline isomerase cyclophilin A, only collection of X-ray diffraction data at ambient temperature allowed an agreement between the crystallographic and NMR functional conformational substates to be obtained (Fraser et al., 2009). The two Asn254 conformers observed here map onto high-probability clusters of torsion-angle distributions obtained from the simulations [yellow and dark grey clusters in Fig. 5(b)]. Asn254 side-chain variability has also been observed under ligand-free conditions (Retailleau $e t$ al., 2004). In the absence of a ligand, UOX has been crystallized in a different space group $\left(P 2_{1}\right)$ with two complete tetramers in the asymmetric unit (PDB entry 1r56; Retailleau et al., 2004). In the $2.6 \AA$ resolution structure at $288 \mathrm{~K}$, Asn 254 samples a range of states that map onto the aqua-green clusters in Fig. 5(b). Conformational heterogeneity for Asn254 therefore appears to be a constitutive property of UOX. In cholesterol oxidase flavoenzyme, an arginine and a glutamate residue at the active site, found in two conformations, have been proposed to control oxygen access to the active-site cavity from a neighbouring channel (Coulombe et al., 2001). It is tempting to suggest that Asn254 dynamics might play a similar role considering that this residue marks the boundary between the active site and an adjacent hydrophobic cavity proposed to act as a transient $\mathrm{O}_{2}$ reservoir (Colloc'h \& Prangé, 2014).

A mechanism for $\mathrm{O}_{2}$ gating facilitated by Asn254 dynamics probably involves $\mathrm{W} 1$ destabilization. MD simulations show that, though the main crystallographic conformation favours long W1 residence times in the peroxo hole, the minor conformation is associated with a higher probability of escaping from it. In fact, this conformation stabilizes W1 outside the peroxo hole at a position consistent with that of the low-occupancy $\mathrm{W}^{\prime}$ in our structure. It is therefore possible that the marginally lower than unitary occupancy for W1 (occupancy 0.93) arises from its fractional mobilization to the $\mathrm{W}^{\prime}$ site promoted by the minor conformation of Asn254. Coupling of Asn254 conformational heterogeneity and W1 stability is further supported by the crystal structure of ligandfree UOX in which Asn254 is visualized adopting multiple alternative rotamers (Retailleau et al., 2004). Here, W1 is observed in only three of the eight independent active sites of the two UOX tetramers present in the asymmetric unit. A mechanism that takes advantage of protein dynamics to 'actively' promote $\mathrm{W} 1 / \mathrm{O}_{2}$ exchange for the oxidation step of catalysis appears particularly useful for cofactor-independent $\mathrm{UOX}$ as $\mathrm{O}_{2}$ affinity for the electrostatically positive active site is presumably rather low. Therefore, similarly to other cofactor-independent $\mathrm{O}_{2}$-metabolizing enzymes such as $\mathrm{DpgC}$, poor ability to concentrate dioxygen in the active site, for example by metal coordination, must be compensated by mechanisms that increase the frequency of $\mathrm{O}_{2}$ entries (Di Russo et al., 2015). Asn254 dynamics is therefore suggested to decrease W1 residence times favouring $\mathrm{O}_{2}$ exchange with the neighbouring hydrophobic pocket.

The availability of the joint neutron/X-ray structures of ${ }^{D}$ UOX-8AZA-W1 allows for an interesting comparison with that of the UOX-8AZA- $\mathrm{Cl}^{-}$complex (PDB entry $4 \mathrm{n} 3 \mathrm{~m}$ ) solved in previous work (Oksanen et al., 2014). Functionally, the key difference between these structures resides in the nature of the molecule present in the peroxo hole (water versus chloride). Thus, comparative analysis is particularly meaningful for active-site residues. While both structures show that $8 \mathrm{AZA}$ is bound as a monoanion deprotonated at N3, differences exist for the important Lys10*-Thr57* dyad (Fig. S7). In UOX-8AZA-Cl- ${ }^{-}$, Lys10* is modelled in the neutral $\mathrm{NH}_{2}$ state accepting a hydrogen bond from Thr57* whose DG1 atom points toward Lys10* ${ }^{* \mathrm{NZ}}$. The authors, however, state that a second conformation (not modelled) might exist in which Lys10* is positively charged $\left(-\mathrm{NH}_{3}^{+}\right)$and the protonated Thr57* hydroxyl group points towards the $\mathrm{Cl}^{-}$ ion. In UOX-8AZA-W1, the catalytic water $\mathrm{W} 1$ is present in

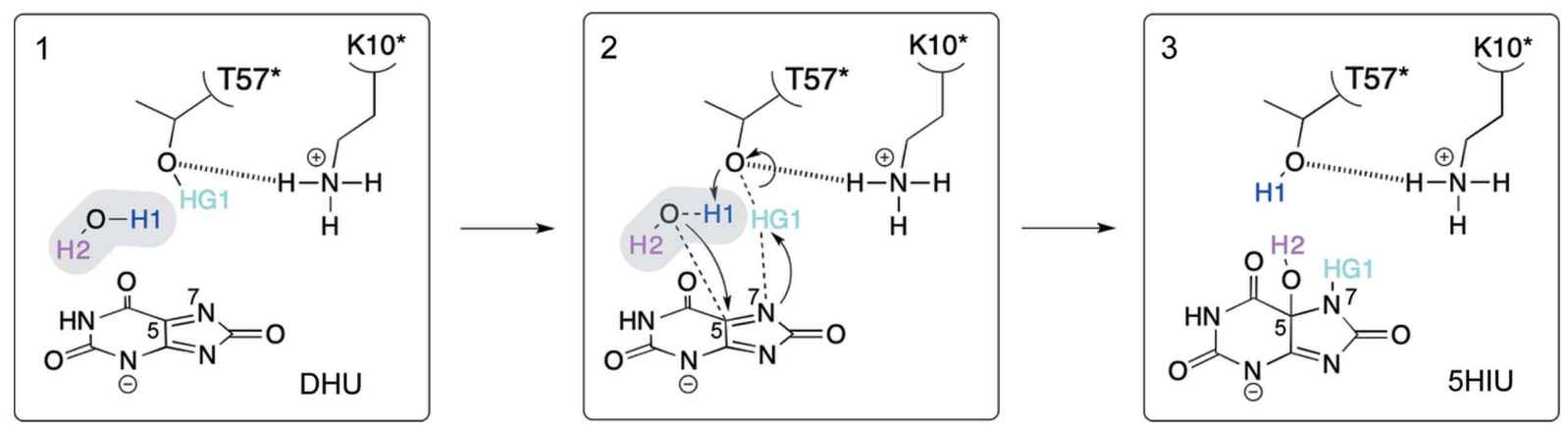

Figure 7

Hydration step. Reaction mechanism for the hydration step in UOX catalysis. 
the peroxo hole as a neutral $\mathrm{H}_{2} \mathrm{O}$ (here we will use $\mathrm{H}$ for both ${ }^{1} \mathrm{H}$ and $\mathrm{D}$ ) oriented at $45^{\circ}$ with respect to the ligand plane and stabilized by a combination of hydrogen bonds. These involve not only the side chains of Thr57* and Asn254 (both conformations) but also an $\mathrm{O}-\mathrm{H} \cdots \pi$ interaction with the 8AZA monoanion. We find clear evidence for a charged Lys10*- $\mathrm{NH}_{3}^{+}$ side chain whilst the Thr57*HG1 atom does not appear to be strongly localized. However, our experiment and simulation agree that the Thr $57^{* \mathrm{OG} 1-\mathrm{HG} 1}$ bond points, on average, in the direction of the ligand, i.e. rotated by almost $180^{\circ}$ compared with what was reported in the presence of chloride. We suggest that differences in active-site protonation states between these structures most likely reflect the nature and charge of the different molecules bound in the peroxo hole. In future work it will therefore be important to determine the neutron structure of the UOX-UA-W1 complex under anaerobic conditions as this has direct implications on the mechanism of substrateinduced $\mathrm{O}_{2}$ activation.

The protonation state observed in our UOX-8AZA-W1 complex is directly relevant for the hydration stage of the reaction mechanism. A recent theoretical study (Wei et al., 2017) proposed the existence of a strong hydrogen-bonding network between charged Lys10*, Thr57*, W1 and $\mathrm{DHU}^{\mathrm{N} 7}$ (note that in their paper the authors use protein numbering for B. subtilis UOX in which Lys9* and Thr69* correspond to A. flavus Lys10* and Thr57*, respectively). As $\mathrm{W}^{\mathrm{O}}$ approaches $\mathrm{DHU} \mathrm{U}^{\mathrm{C} 5}$ in the nucleophilic attack, $\mathrm{W} 1^{\mathrm{H} 1}$ comes close to Thr57*OG1 while HG1 gradually forms a bond with $\mathrm{DHU}^{\mathrm{N} 7}$ changing the $\mathrm{C} 5=\mathrm{N} 7$ double bond to a single bond (Fig. 7). In this mechanism the positively charged Lys10* stabilizes the negative charge on Thr57* during the transition state. Our structural data and simulation results are fully consistent with this proposal. Specifically, the charged Lys10* side chain favours the orientation of the Thr $57^{* \text { OG1-HG1 }}$ bond toward the $\pi$ system of the ligand, thus facilitating proton transfer to N7. As $\mathrm{W} 1^{\mathrm{O}}$ is oriented toward $\mathrm{C} 5$, nucleophilic attack is expected to occur on this atom (instead of $\mathrm{C} 4$ ) while $\mathrm{Thr57*}$ regains neutrality by abstracting the $\mathrm{H} 1$ proton from $\mathrm{W} 1$. Thr $57^{\mathrm{HG} 1}$ is therefore central to a Lys10- $\mathrm{NH}_{3}^{+}$-assisted proton-relay system.

\section{Acknowledgements}

We thank the ESRF for access to the BM30A beamline and Dr Jean-Luc Ferrer for assisting LMcG during data collection. Dr Luca Signor (IBS, Grenoble) is acknowledged for his help with the mass spectrometry analysis.

\section{Funding information}

LMcG is supported by an ILL-sponsored $\mathrm{PhD}$ studentship awarded to RAS and MPB. SB is funded by BBSRC grant BB/ P000169/1 awarded to RAS and ER. The authors thank the ILL for access to the Deuteration Laboratory (proposal No. DL-03-189) and for the provision of beam time on the LADIIII diffractometer (proposal Nos. 8-01-490, 8-01-522, 8-01549). This work used the platforms of the Grenoble InstructERIC center (ISBG; UMS 3518 CNRS-CEA-UGA-EMBL) within the Grenoble Partnership for Structural Biology (PSB), supported by FRISBI (grant No. ANR-10-INBS-05-02) and GRAL, financed within the University Grenoble Alpes graduate school (Ecoles Universitaires de Recherche) $\mathrm{CBH}$ EUR-GS (grant No. ANR-17-EURE-0003). ER also acknowledges EPSRC (EP/R013012/1) and ERC (project 757850 BioNet) grants. The authors acknowledge use of the research computing facility at King's College London, Rosalind.

\section{References}

Afonine, P. V., Moriarty, N. W., Mustyakimov, M., Sobolev, O. V., Terwilliger, T. C., Turk, D., Urzhumtsev, A. \& Adams, P. D. (2015). Acta Cryst. D71, 646-666.

Afonine, P. V., Mustyakimov, M., Grosse-Kunstleve, R. W., Moriarty, N. W., Langan, P. \& Adams, P. D. (2010). Acta Cryst. D66, 11531163.

Andersen, H. C. (1983). J. Comput. Phys. 52, 24-34.

Arzt, S., Campbell, J. W., Harding, M. M., Hao, Q. \& Helliwell, J. R. (1999). J. Appl. Cryst. 32, 554-562.

Becke, A. D. (1993). J. Chem. Phys. 98, 5648-5652.

Blakeley, M. P. \& Podjarny, A. (2018). Emerg. Top. Life Sci. 2, 39-55.

Blakeley, M. P., Teixeira, S. C. M., Petit-Haertlein, I., Hazemann, I., Mitschler, A., Haertlein, M., Howard, E. \& Podjarny, A. D. (2010). Acta Cryst. D66, 1198-1205.

Breneman, C. M. \& Wiberg, K. B. (1990). J. Comput. Chem. 11, 361373.

Brooks, B. R., Brooks, C. L., Mackerell, A. D. Jr, Nilsson, L., Petrella, R. J., Roux, B., Won, Y., Archontis, G., Bartels, C., Boresch, S., Caflisch, A., Caves, L., Cui, Q., Dinner, A. R., Feig, M., Fischer, S., Gao, J., Hodoscek, M., Im, W., Kuczera, K., Lazaridis, T., Ma, J., Ovchinnikov, V., Paci, E., Pastor, R. W., Post, C. B., Pu, J. Z., Schaefer, M., Tidor, B., Venable, R. M., Woodcock, H. L., Wu, X., Yang, W., York, D. M. \& Karplus, M. (2009). J. Comput. Chem. 30, 1545-1614.

Bui, S. \& Steiner, R. A. (2016). Curr. Opin. Struct. Biol. 41, 109-118.

Bui, S., von Stetten, D., Jambrina, P. G., Prangé, T., Colloc'h, N., de Sanctis, D., Royant, A., Rosta, E. \& Steiner, R. A. (2014). Angew. Chem. Int. Ed. 53, 13710-13714.

Campbell, J. W. (1995). J. Appl. Cryst. 28, 228-236.

Colloc'h, N., el Hajji, M., Bachet, B., L'Hermite, G., Schiltz, M., Prangé, T., Castro, B. \& Mornon, J. P. (1997). Nat. Struct. Biol. 4, 947-952.

Colloc'h, N. \& Prangé, T. (2014). FEBS Lett. 588, 1715-1719.

Colloc'h, N., Sopkova-de Oliveira Santos, J., Retailleau, P., Vivarès, D., Bonneté, F., Langlois d'Estainto, B., Gallois, B., Brisson, A., Risso, J. J., Lemaire, M., Prangé, T. \& Abraini, J. H. (2007). Biophys. J. 92, 217-224.

Coulombe, R., Yue, K. Q., Ghisla, S. \& Vrielink, A. (2001). J. Biol. Chem. 276, 30435-30441.

Darden, T., York, D. \& Pedersen, L. (1993). J. Chem. Phys. 98, 10089 10092.

DeLano, W. L. (2002). CCP4 Newsl. Protein Crystallogr. 40, 82-92.

Di Russo, N. V., Condurso, H. L., Li, K., Bruner, S. D. \& Roitberg, A. E. (2015). Chem. Sci. 6, 6341-6348.

Emsley, P., Lohkamp, B., Scott, W. G. \& Cowtan, K. (2010). Acta Cryst. D66, 486-501.

Evans, P. (2006). Acta Cryst. D62, 72-82.

Fetzner, S. \& Steiner, R. A. (2010). Appl. Microbiol. Biotechnol. 86, 791-804.

Fisher, S. J., Blakeley, M. P., Howard, E. I., Petit-Haertlein, I., Haertlein, M., Mitschler, A., Cousido-Siah, A., Salvay, A. G., Popov, A., Muller-Dieckmann, C., Petrova, T. \& Podjarny, A. (2014). Acta Cryst. D70, 3266-3272. 
Fraser, J. S., Clarkson, M. W., Degnan, S. C., Erion, R., Kern, D. \& Alber, T. (2009). Nature, 462, 669-673.

Fraser, J. S., van den Bedem, H., Samelson, A. J., Lang, P. T., Holton, J. M., Echols, N. \& Alber, T. (2011). Proc. Natl Acad. Sci. USA, 108, 16247-16252.

Frauenfelder, H., Hartmann, H., Karplus, M., Kuntz, I. D. Jr, Kuriyan, J., Parak, F., Petsko, G. A., Ringe, D., Tilton, R. F. Jr \& Connolly, M. L. (1987). Biochemistry, 26, 254-261.

Frauenfelder, H., Petsko, G. A. \& Tsernoglou, D. (1979). Nature, 280, 558-563.

French, S. \& Wilson, K. (1978). Acta Cryst. A34, 517-525.

Frisch, M. J., Trucks, G. W., Schlegel, H. B., Scuseria, G. M., Robb, M. A., Cheeseman, J. R., Scalmani, G., Barone, V., Mennucci, B., Petersson, G. A., Nakatsuji, H., Caricato, M., Li, X., Hratchian, H. P., Izmaylov, A. F., Bloino, J., Zheng, G., Sonnenberg, J. L., Hada, M., Ehara, M., Toyota, K., Fukuda, R., Hasegawa, J., Ishida, M., Nakajima, T., Honda, Y., Kitao, O., Nakai, H., Vreven, T., Montgomery, J. A. Jr, Peralta, J. E., Ogliaro, F., Bearpark, M., Heyd, J. J., Brothers, E., Kudin, K. N., Staroverov, V. N., Keith, T., Kobayashi, R., Normand, J., Raghavachari, K., Rendell, A., Burant, J. C., Iyengar, S. S., Tomasi, J., Cossi, M., Rega, N., Millam, J. M., Klene, M., Knox, J. E., Cross, J. B., Bakken, V., Adamo, C., Jaramillo, J., Gomperts, R., Stratmann, R. E., Yazyev, O., Austin, A. J., Cammi, R., Pomelli, C., Ochterski, J. W., Martin, R. L., Morokuma, K., Zakrzewski, V. G., Voth, G. A., Salvador, P., Dannenberg, J. J., Dapprich, S., Daniels, A. D., Farkas, O., Foresman, J. B., Ortiz, J. V., Cioslowski, J. \& Fox, D. J. (2013). Gaussian09. Gaussian, Inc., Wallingford CT, USA.

Gabison, L., Chiadmi, M., El Hajji, M., Castro, B., Colloc'h, N. \& Prangé, T. (2010). Acta Cryst. D66, 714-724.

Gabison, L., Prangé, T., Colloc'h, N., El Hajji, M., Castro, B. \& Chiadmi, M. (2008). BMC Struct. Biol. 8, 32.

Garman, E. F. (2010). Acta Cryst. D66, 339-351.

Grimme, S., Ehrlich, S. \& Goerigk, L. (2011). J. Comput. Chem. 32, $1456-1465$.

Haertlein, M., Moulin, M., Devos, J. M., Laux, V., Dunne, O. \& Forsyth, V. T. (2016). Methods Enzymol. 566, 113-157.

Hibi, T., Kume, A., Kawamura, A., Itoh, T., Fukada, H. \& Nishiya, Y. (2016). Biochemistry, 55, 724-732.

Huggins, D. J., Biggin, P. C., Dämgen, M. A., Essex, J. W., Harris, S. A., Henchman, R. H., Khalid, S., Kuzmanic, A., Laughton, C. A., Michel, J., Mulholland, A. J., Rosta, E., Sansom, M. S. P. \& van der Kamp, M. W. (2019). WIREs Comput. Mol. Sci. 9, e1393.

Imhoff, R. D., Power, N. P., Borrok, M. J. \& Tipton, P. A. (2003). Biochemistry, 42, 4094-4100.

Jo, S., Kim, T., Iyer, V. G. \& Im, W. (2008). J. Comput. Chem. 29, 1859 1865.

Kahn, K. (1999). Bioorg. Chem. 27, 351-362.

Kahn, K., Serfozo, P. \& Tipton, P. A. (1997). J. Am. Chem. Soc. 119, 5435-5442.

Kahn, K. \& Tipton, P. A. (1997). Biochemistry, 36, 4731-4738.

Kahn, K. \& Tipton, P. A. (1998). Biochemistry, 37, 11651-11659.

Koruza, K., Lafumat, B., Nyblom, M., Mahon, B. P., Knecht, W., McKenna, R. \& Fisher, S. Z. (2019). Acta Cryst. D75, 895903.

Krishnan, R., Binkley, J. S., Seeger, R. \& Pople, J. A. (1980). J. Chem. Phys. 72, 650-654.

Liebschner, D., Afonine, P. V., Baker, M. L., Bunkóczi, G., Chen, V. B., Croll, T. I., Hintze, B., Hung, L.-W., Jain, S., McCoy, A. J., Moriarty, N. W., Oeffner, R. D., Poon, B. K., Prisant, M. G., Read, R. J., Richardson, J. S., Richardson, D. C., Sammito, M. D., Sobolev, O. V., Stockwell, D. H., Terwilliger, T. C., Urzhumtsev, A. G., Videau, L. L., Williams, C. J. \& Adams, P. D. (2019). Acta Cryst. D75, 861-877.

Logan, D. T. (2020). Methods Enzymol. 634, 201-224.

Marchetti, M., Liuzzi, A., Fermi, B., Corsini, R., Folli, C., Speranzini, V., Gandolfi, F., Bettati, S., Ronda, L., Cendron, L., Berni, R., Zanotti, G. \& Percudani, R. (2016). Sci. Rep. 6, 38302.
McLean, A. D. \& Chandler, G. S. (1980). J. Chem. Phys. 72, 56395648.

Oda, M., Satta, Y., Takenaka, O. \& Takahata, N. (2002). Mol. Biol. Evol. 19, 640-653.

Oksanen, E., Blakeley, M. P., El-Hajji, M., Ryde, U. \& BudayovaSpano, M. (2014). PLoS One, 9, e86651.

Pfrimer, P., de Moraes, L. M., Galdino, A. S., Salles, L. P., Reis, V. C., De Marco, J. L., Prates, M. V., Bloch, C. Jr \& Torres, F. A. (2010). J. Biomed. Biotechnol. 2010, 674908.

Phillips, J. C., Braun, R., Wang, W., Gumbart, J., Tajkhorshid, E., Villa, E., Chipot, C., Skeel, R. D., Kalé, L. \& Schulten, K. (2005). J. Comput. Chem. 26, 1781-1802.

Phillips, J. C., Hardy, D. J., Maia, J. D. C., Stone, J. E., Ribeiro, J. V., Bernardi, R. C., Buch, R., Fiorin, G., Hénin, J., Jiang, W., McGreevy, R., Melo, M. C. R., Radak, B. K., Skeel, R. D., Singharoy, A., Wang, Y., Roux, B., Aksimentiev, A., LutheySchulten, Z., Kalé, L. V., Schulten, K., Chipot, C. \& Tajkhorshid, E. (2020). J. Chem. Phys. 153, 044130.

Ramazzina, I., Folli, C., Secchi, A., Berni, R. \& Percudani, R. (2006). Nat. Chem. Biol. 2, 144-148.

Rasmussen, B. F., Stock, A. M., Ringe, D. \& Petsko, G. A. (1992). Nature, 357, 423-424.

Ravelli, R. B. \& McSweeney, S. M. (2000). Structure, 8, 315-328.

Retailleau, P., Colloc'h, N., Vivarès, D., Bonneté, F., Castro, B., El Hajji, M., Mornon, J.-P., Monard, G. \& Prangé, T. (2004). Acta Cryst. D60, 453-462.

Shao, Y., Gan, Z., Epifanovsky, E., Gilbert, A. T. B., Wormit, M., Kussmann, J., Lange, A. W., Behn, A., Deng, J., Feng, X., Ghosh, D., Goldey, M., Horn, P. R., Jacobson, L. D., Kaliman, I., Khaliullin, R. Z., Kuś, T., Landau, A., Liu, J., Proynov, E. I., Rhee, Y. M., Richard, R. M., Rohrdanz, M. A., Steele, R. P., Sundstrom, E. J., Woodcock, H. L. III, Zimmerman, P. M., Zuev, D., Albrecht, B., Alguire, E., Austin, B., Beran, G. J. O., Bernard, Y. A., Berquist, E., Brandhorst, K., Bravaya, K. B., Brown, S. T., Casanova, D., Chang, C.., Chen, Y., Chien, S. H., Closser, K. D., Crittenden, D. L., Diedenhofen, M., DiStasio, R. A. Jr., Do, H., Dutoi, A. D., Edgar, R. G., Fatehi, S., Fusti-Molnar, L., Ghysels, A., Golubeva-Zadorozhnaya, A., Gomes, J., Hanson-Heine, M. W. D., Harbach, P. H. P., Hauser, A. W., Hohenstein, E. G., Holden, Z. C., Jagau, T.., Ji, H., Kaduk, B., Khistyaev, K., Kim, J., Kim, J., King, R. A., Klunzinger, P., Kosenkov, D., Kowalczyk, T., Krauter, C. M., Lao, K. U., Laurent, A. D., Lawler, K. V., Levchenko, S. V., Lin, C. Y., Liu, F., Livshits, E., Lochan, R. C., Luenser, A., Manohar, P., Manzer, S. F., Mao, S.., Mardirossian, N., Marenich, A. V., Maurer, S. A., Mayhall, N. J., Neuscamman, E., Oana, C. M., Olivares-Amaya, R., O'Neill, D. P., Parkhill, J. A., Perrine, T. M., Peverati, R., Prociuk, A., Rehn, D. R., Rosta, E., Russ, N. J., Sharada, S. M., Sharma, S., Small, D. W., Sodt, A., Stein, T., Stück, D., Su, Y.., Thom, A. J. W., Tsuchimochi, T., Vanovschi, V., Vogt, L., Vydrov, O., Wang, T., Watson, M. A., Wenzel, J., White, A., Williams, C. F., Yang, J., Yeganeh, S., Yost, S. R., You, Z.., Zhang, I. Y., Zhang, X., Zhao, Y., Brooks, B. R., Chan, G. K. L., Chipman, D. M., Cramer, C. J., Goddard, W. A. III, Gordon, M. S., Hehre, W. J., Klamt, A., Schaefer, H. F. III, Schmidt, M. W., Sherrill, C. D., Truhlar, D. G., Warshel, A., Xu, X., AspuruGuzik, A., Baer, R., Bell, A. T., Besley, N. A., Chai, J.., Dreuw, A., Dunietz, B. D., Furlani, T. R., Gwaltney, S. R., Hsu, C.., Jung, Y., Kong, J., Lambrecht, D. S., Liang, W., Ochsenfeld, C., Rassolov, V. A., Slipchenko, L. V., Subotnik, J. E., Van Voorhis, T., Herbert, J. M., Krylov, A. I., Gill, P. M. W. \& Head-Gordon, M. (2015). Mol. Phys. 113, 184-215.

Shu, F., Ramakrishnan, V. \& Schoenborn, B. P. (2000). Proc. Natl Acad. Sci. USA, 97, 3872-3877.

Steiner, T. \& Koellner, G. (2001). J. Mol. Biol. 305, 535-557.

Terkeltaub, R. (2010). Nat. Rev. Rheumatol. 6, 30-38.

Tilton, R. F. Jr, Dewan, J. C. \& Petsko, G. A. (1992). Biochemistry, 31, 2469-2481.

Wei, D., Huang, X., Qiao, Y., Rao, J., Wang, L., Liao, F. \& Zhan, C. G. (2017). ACS Catal. 7, 4623-4636. 
Weik, M., Ravelli, R. B., Kryger, G., McSweeney, S., Raves, M. L., Harel, M., Gros, P., Silman, I., Kroon, J. \& Sussman, J. L. (2000). Proc. Natl Acad. Sci. USA, 97, 623-628.

Winn, M. D., Ballard, C. C., Cowtan, K. D., Dodson, E. J., Emsley, P., Evans, P. R., Keegan, R. M., Krissinel, E. B.,
Leslie, A. G. W., McCoy, A., McNicholas, S. J., Murshudov, G. N., Pannu, N. S., Potterton, E. A., Powell, H. R., Read, R. J., Vagin, A. \& Wilson, K. S. (2011). Acta Cryst. D67, 235242.

Winter, G. (2010). J. Appl. Cryst. 43, 186-190. 